UNIVERSIDADE DE SÃO PAULO

INSTITUTO DE GEOCIÊNCIAS

\title{
TAFONOMIA E PALEOECOLOGIA DE BIVALVES PERMIANOS EM FÁCIES SILICICLÁSTICAS DEFICIENTES EM OXIGÊNIO: O EXEMPLO DAS FORMAÇÕES IRATI E SERRA ALTA, BACIA DO PARANÁ, BRASIL
}

Suzana Aparecida Matos da Silva

Orientador: Prof. Dr. Marcello Guimarães Simões

\section{TESE DE DOUTORADO}

Programa de Pós-Graduação em Geoquímica e Geotectônica

SÃO PAULO

2016 


\title{
TAFONOMIA E PALEOECOLGIA DE BIVALVES PERMIANOS EM FÁCIES SILICICLÁSTICAS DEFICIENTES EM OXIGÊNIO: O EXEMPLO DAS FORMAÇÕES IRATI E SERRA ALTA, BACIA DO PARANÁ, BRASIL.
}

\begin{abstract}
Tese apresentada ao Instituto de Geociências da Universidade de São Paulo, como parte dos requisitos para a obtenção do título de Doutor em Ciências.

Versão corrigida contendo as alterações solicitadas pela comissão julgadora em 28 de julho de 2016. A versão original encontra-se no acervo da biblioteca do Instituto de Geociências/USP, de acordo com a resolução CoPGr 5890, de 20 de dezembro de 2010.

Área de Concentração: Geotectônica.

Orientador: Prof. Dr. Marcello Guimarães Simões
\end{abstract}


Autorizo a reprodução e divulgação total ou parcial deste trabalho, por qualquer meio convencional ou eletrônico, para fins de estudo e pesquisa, desde que citada a fonte.

Ficha catalográfica preparada pelo Serviço de Biblioteca e Documentação do Instituto de Geociências da Universidade de São Paulo

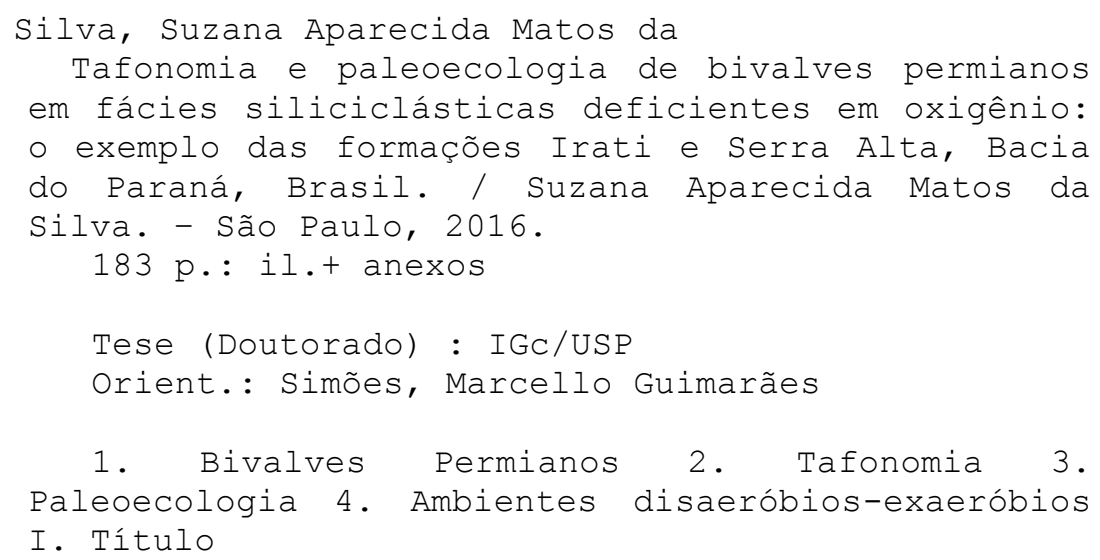


Dedico este trabalho aos meus pais Maria Aparecida e João pelo amor, apoio e incentivo aos meus estudos. 


\section{AGRADECIMENTOS}

Agradeço a minha família, Maria Aparecida, João, João Adolfo e Elaine Matos da Silva pelo amor gigante que sempre tiveram por mim, pelo apoio, conselhos, cuidados e o companheirismo de todos os dias.

Ao Prof. Dr. Marcello Guimarães Simões (IBB/UNESP), pela orientação, pela paciência, ensinamentos científicos, didáticos, burocráticos, entre outros, e pelas inúmeras oportunidades de crescimento profissional.

Aos Profs. Drs. Mario L. Assine (IGCE/UNESP), Lucas V. Warren (IGCE/UNESP), Claudio Riccomini (IEE/USP) e ao geólogo Filipe G. Varejão (IGCE/UNESP), pela participação em campo, pelas discussões e colaborações nos artigos, pelos ensinamentos.

À Profa. Dra. Juliana de Moraes Leme (IGc/USP), por estar sempre disposta a ajudar mesmo que não seja a sua obrigação. Pelos almoços, conversas e risadas. Pela companhia nos congressos. Pela amizade e carinho.

Aos professores que participaram da minha banca da qualificação, Prof. Dr. Setembrino Petri e Profa. Dra. Maria Judite Garcia pela disposição, pelos comentários e discussões.

Ao Me. Cristiano Ng (Petrobrás) e a Profa. Dra. Rosemarie Rohn Davies (IGce - UNESP/Rio Claro), por disponibilizar informações a respeito de depósitos da Formação Serra Alta na região de Rio Claro-SP.

Ao Prof. Dr. Luiz Eduardo Anelli (IGc/USP), pelas aulas de fotografia e descrição de espécies. Pelas conversas e risadas.

Ao Professor Marcelo Adorna Fernandes (DEBE/UFSCar) por doar amostras de Tambaquyra camargoi coletadas na Pedreira Partecal Partezani.

À Juliana Machado David, pela ajuda com os textos e com os trabalhos de campo. Pelos desabafos e conselhos. Pelas conversas sem fim. Pela companhia, pelo bom senso de sempre e pela amizade tão querida.

À Jacqueline Peixoto Neves (IBB/UNESP), pela ajuda no laboratório, nos trabalhos de campo, nas dúvidas de todos os dias. Pelas conversas, pela companhia nos dias bons e ruins. Pela amizade.

À Bruna Pozzi Rufato, por me abrigar enquanto eu fazia as disciplinas em São Paulo. Pelas "gordices" e bobeiras. Por ter sempre ideias ótimas pra dizer e propor em todas as situações. Pela amizade indispensável.

Ao Ronaldo Fogueiral, pelo amor, apoio e companheirismo. Por sempre se oferecer em ajudar. Por aguentar meu bom e mau humor e sempre estar disposto a ouvir.

Ao João Bondioli, pela ajuda nos trabalhos de laboratório e campo. Por compartilhar discussões e "dúvidas lamosas". 
Ao Vitor Guerrini, Heitor Sartorelli e ao Filipe dos Santos pela ajuda no laboratório e em campo. Pelas risadas nos cafés.

Ao Departamento de Zoologia e ao Laboratório de Paleozoologia Evolutiva (IBB UNESP/Botucatu), pelo uso de sua infraestrutura, e coleções cinetíficas.

Ao Instituto de Geociências da USP, pelo uso das suas instalações e laboratórios.

Aos secretários e funcionários do IGc - USP e do IBB - UNESP , em especial Katherine e Leonardo (IGc-USP), e Juliana, Silvio, Hamilton e Flávio (IBB-UNESP), pela paciência, educação e atenção de sempre.

À Botupedras, por sempre nos ajudar com os cortes em amostras, muitas vezes atrapalhando o funcionamento da marmoraria.

À Fapesp, pelo auxílio financeiro ao projeto (Processo: 2012/12508-6), o que permitiu não apenas a execução do projeto, mas também minha dedicação exclusiva a pós graduação. 
“A descoberta consiste em ver o que todo mundo viu e pensar o que ninguém pensou." (Albert Szent-Györgyi) 


\section{RESUMO}

Fácies sedimentares geradas em ambientes restritos, pobres em oxigênio são comuns no registro geológico de vários mares epicontinentais (bacias intracratônicas), sendo particularmente frequentes em trato de sistemas transgressivos de várias sucessões paleozoicas, mesozoicas e cenozoicas. A primeira vista, são constituídas por sucessões monótonas de folhelhos negros ou argilitos, pobres em fósseis, supostamente geradas em condições estáveis de anoxia ou baixas taxas de concentrações de oxigênio. Durante o Paleozoico tardio, a bacia intracratônica do Paraná, localizada no centro-oeste do Gondwana, constituíu um imenso (>1.600.00 $\mathrm{km}^{2}$ ) mar epicontinental raso e isolado do Oceano Pantalássico. Na sucessão permiana da Bacia do Paraná (Grupo Passa Dois), fácies sedimentares pobres em oxigênio são comuns na Formação Irati (Kunguriano/Artinskiano), rica em Mesosaurus, e na Formação Serra Alta (Roadiano/Wordiano), sobrejacente. Em contraste ao vasto conhecimento que se tem a respeito dos depósitos coevos, de águas rasas da Formação Teresina, onde arenitos bioclásticos e coquinas são comuns, pouco é conhecido sobre a gênese, composição taxonômica e paleoecologia das faunas bentônicas que viveram durante a deposição das formações Irati e Serra Alta. Análises sedimentológicas, tafonômicas e paleontológicas detalhadas na sucessão basal de ambas as unidades, a partir de afloramentos nos estados do Paraná e São Paulo, revelaram que essas possuem histórias deposicionais dinâmicas e complexas. Fundamentado em características texturais (presença/ausência de laminação primária, bioturbação), em ocorrências de conchas de bivalves (autóctones/parautóctones) e na presença/ausência de níveis ricos em concreções ou nódulos fosfáticos, são relatadas variações nas concentrações de oxigênio das águas intersticiais e de fundo, batimetria, taxas de sedimentação e alterações na colonização bentônica para determinados intervalos estratigráficos de ambas as unidades litoestratigráficas. Ao contrário dos depósitos de águas rasas da Formação Teresina, os da Formação Irati são extremamente pobres em invertebrados bentônicos. Neste contexto, é notável a preservação de abundantes bivalves endêmicos de infauna rasa, nos folhelhos da porção basal da Formação Irati. Sua presença em depósitos de costa à fora (offshore) é resultado de transporte por fluxos de tempestade que retiraram conchas diminutas, que colonizaram águas mais rasas e oxigenadas e as levaram para as porções mais distais da plataforma (abaixo do nível de base de ondas de tempestades). Posteriormente, as conchas foram selecionadas e orientadas por correntes de longa duração atuando na plataforma, produzindo pavimentos densos $\left(>90\right.$ conchas $\left./ 20 \mathrm{~cm}^{2}\right)$, ricos em conchas, nos quais as valvas estão preservadas em posição hidrodinamicamente estável (com a convexidade voltada para cima), formando concentrações complexas de 
conchas, apesar de suas feições internas (microestratigrafia) serem simples. Os novos dados apresentados aqui pela primeira vez possuem importantes implicações paleoecológicas, paleogeográficas e evolutivas que indicam que (a) durante a deposição dos folhelhos betuminosos da Formação Irati, a despeito das condições de anoxia, abundante fauna de bivalves colonizou as águas rasas, marginais contemporâneas da Bacia do Paraná; (b) a natureza mono-/paucispecífica dos pavimentos ricos em bivalves é, em parte, resultado do transporte hidráulico das conchas; e (c) durante a deposição da porção basal da Formação Irati (Membro Taquaral) houve restrição da conexão oceânica, já que a fauna encontrada nos pavimentos é endêmica. Portanto, a origem da famosa malacofauna do Grupo Passa Dois ocorreu em algum momento entre o intervalo de deposição da Formação Palermo, subjacente, e a porção basal da Formação Irati, sobrejacente. Assim sendo, os bivalves endêmicos dessa unidade surgiram ao menos $\sim 10$ milhões de anos antes do que anteriormente pensado. Os dados obtidos indicam também que a deposição da sucessão dominada por argilitos, da porção basal da Formação Serra Alta se deu também sob complexa interação de fatores paleoambientais, com flutuações nas taxas de sedimentação e oxigenação de fundo, provavelmente relacionadas a variações climáticas ou tectonicamente induzidas. Os macrofósseis bentônicos estão distribuídos de forma difusa nesta unidade e apenas em alguns níveis se tornam mais abundantes, geralmente no interior de concreções carbonáticas, comuns na porção basal da unidade. Esse fato indica que as condições essenciais para o desenvolvimento de concreções existiram apenas em um intervalo particular da Formação Serra Alta. As fácies sedimentares argilosas ricas em concreções registram três diferentes paleocomunidades bentônicas, incluindo (a) fauna residente adaptada a condições pobres em oxigênio (i.e. pequenos bivalves suspensívoros de infauna pertencentes às espécies Rioclaroa lefevrei, Barbosaia angulata e Ferrazia simplicicarinata que ocorrem associados a traços fósseis do gênero Planolites), (b) táxons quimiossimbiontes, habitando substratos tóxicos (disóxicos extremos) (i.e. bivalves gigantes de infauna, tais como Anhembia froesi, Maackia contorta e Tambaquyra camargoi), e (c) populações eventuais habitando substratos (óxicos/disóxicos) após perturbações de fundo de curto prazo (i.e. traços Planolites e Thalassionoides). No contexto paleoambiental acima, é descrita pela primeira vez uma fauna permiana dominada por bivalves com formas incomuns associados a prováveis exsudações de metano e/ou outros hidrocarbonetos. Argilitos de coloração cinza escura da Formação Serra Alta, aflorando no km 160,7 da Rodovia Castello Branco, município de Porangaba, Estado de São Paulo, apresentam dois horizontes principais ricos em concreções carbonáticas. Dentro das concreções, conchas de bivalves com grandes dimensões (Anhembia froesi, Tambaquyra 
camargoi e Maackia contorta) estão preservadas. Espécimes de Tambaquyra camargoi podem ser até dez vezes maiores do que os pequenos bivalves encontrados dispersos nos argilitos lateralmente equivalentes da mesma unidade. Intercalada entre os dois horizontes ricos em concreções carbonáticas é encontrada uma camada de calcário brechado, de geometria tabular, e de espessura centimétrica, com laminações provavelmente produzidas por comunidade microbial. Em algumas partes do calcário brechado são observadas estruturas verticais, do tipo flame, formadas por injeções de argilitos altamente bioturbados. A laminação é difusa e os traços horizontais estão alinhados devido à compactação do sedimento. Imediatamente acima, argilitos formam pequenas estruturas dômicas, com a porção central ligeiramente deprimida $(=$ mounds $)$. Tubos horizontais centimétricos e concentrações monoespecíficas de conchas articuladas de Tambaquyra camargoi, estão preservadas na base destas estruturas elevadas. O calcário brechado e estruturas associadas (i.e., mounds) são recobertos por argilitos cinza escuros afossilíferos. Os valores de isótopos de carbono ( $\delta 13 \mathrm{C})$ para (a) a camada carbonática brechada, (b) argilitos bioturbados, (c) concreções carbonáticas e (d) conchas de bivalves encontradas dentro das concreções carbonáticas são todos negativos $(\sim 6,1-7,6 \%$ ). Esses valores indicam que a precipitação do carbonato pode ter sido resultado da oxidação do metano ou outros hidrocarbonetos mediada por bactérias. O intervalo que contém a camada de carbonato e estruturas dômicas (= mounds) associadas está cerca de $~ 8,7$ metros acima do contato entre a Formação Irati, subjancente, e a Formação Serra Alta, sobrejacente. A primeira unidade litoestratigráfica é conhecida pelo seu alto teor de carbono orgânico total (maiores que 17\%) e presença de enxofre. As evidências acima apontam para a presença de um sistema de exsudações ativas de metano e outros hidrocarbonetos no fundo da bacia durante os tempos Serra Alta. Nos locais onde a água intersticial rica em sulfetos era liberada, o substrato era colonizado por bivalves quimiossimbiontes. Ao contrário dos clássicos sistemas de exsudação de metano, registrados ao longo de limites de placas, em bacias de margem ativa, o exemplo aqui descrito está relacionado à compactação de sedimentos ricos em matéria orgânica em bacia intracratônica. As espécies acima pertencem à Família Pachydomidae, que inclui bivalves suspensívoros,de infauna que foi dominante entre os representantes da malacofauna endêmica do Grupo Passa Dois. Consequentemente, eles não são relacionados aos "clássicos" bivalves quimiossimbiontes, com representantes viventes (Bathymodiolinae, Solemyidae, Thyasiridae, Lucinellidae, Vesicomyidae). Os bivalves quimiossimbiontes da Formação Serra Alta foram, provavelmente, originados a partir de rápida radiação adaptativa intrabasinal de elementos de 
águas rasas que colonizaram fundos anóxicos/disóxicos da Bacia do Paraná, durante os "tempos" Irati-Serra Alta.

\begin{abstract}
Oxygen-deficient facies dominate the sedimentary record of various epeiric seas (intraplate basins) and are particularly common in the transgressive systems tract of several Paleozoic, Mesozoic and Cenozoic sequences. At the first glance, they are materialized by monotonous, fossil-poor (barren) successions of black shales and/or mudstones thought to be generated under stable conditions of oxygen depletion. During the late Paleozoic, the intracratonic Paraná Basin, Brazil, in the central-western Gondwanaland, was covered by a large $\left(>1.600 .000 \mathrm{~km}^{2}\right)$, shallow and isolated epeiric sea. Within the Permian succession, oxygen-deficient facies are commonly recorded in the Mesosaurus-bearing Irati Formation (Kungurian/Artinskian) and the overlain Serra Alta Formation (Roadian/Wordian) of the Passa Dois Group. In contrast to the coeval shallow water deposits of the Teresina Formation, where shell-rich sandstones and shell beds are common, little is known about the genesis, taxonomic composition, and paleoecology of the benthic faunas that thrived during the deposition of the Irati and Serra Alta formations. Detailed sedimentological, taphonomic and paleontological surveys in these units have revealed, however, a dynamic and complex depositonal history. Based on textural features (presence/absence of primary lamination, bioturbation), autochthonous to parautochthonous occurrences of shelly benthic invertebrates (bivalves) and the presence/absence of concretion-bearing and phosphate-rich layers, we report variations in the bottom and pore water oxygen levels, bathymetry, sedimentation rates, and changes in benthic substrate colonization for certain stratigraphical intervals of both units. In contrast with the shallow water deposits of the Teresina Formation, benthic invertebrates were extremely rare in the Irati Formation. In this context, the abundant shallow-burrowing, endemic bivalves recorded in shales of its basal part are one of the most distinctive features of this stratigraphic interval. Their preservation in offshore deposits is, however, a product of storm flows in shallow waters that swept minute shells to distal settings. Subsequently, these were sorted and oriented by long-lasting shelf currents that produced dense ( $>90$ shells $/ 20$ $\mathrm{cm}^{2}$ ) shell pavements in which the valves are preserved in a hydrodynamically stable posture (convex-up), forming complex shell concentrations despite their simple internal stratigraphy. The new data presented here have important paleoecologic, paleogeographic and evolutionary implications and indicate that (a) during the anoxic deposition of the oil-rich shales of the Irati Formation, numerous benthic invertebrates thrived in the contemporary shallow-water
\end{abstract}


bottoms of the Paraná Basin; (b) the mono- to paucispecific nature of the studied bivalve-rich pavements is, in part, due to hydrologic shell transport; and (c) restricted connections to open ocean waters (Panthalassa) existed during Irati times. Therefore, the origin of the endemic Passa Dois molluscan fauna occurred somewhere between the interval represented by the underlying Palermo Formation and the basal portion of the Irati Formation. These endemic bivalves appeared at least $\sim 10$ million years earlier than previously thought. Our data also indicate that the deposition of the "apparently sterile" mudstone-dominated succession of the basal part of the Serra Alta Formation was driven by a complex interplay of paleoenvironmental factors (variations in sedimentation rate and oxygen pulses) tied to tectonic and climate changes. Benthic macrofossils are scattered distributed in this unit, and only in a few occurrences they may be abundant, usually inside carbonate concretions, which are common in the basal part of this unit. This indicates that the conditions essential for concretion development existed only at particular stratigraphical intervals of the Serra Alta Formation. The concretion-bearing mudstone facies of the Serra Alta Formation may record three distinct benthic paleocommunities, including resident adapted to: (a) normal background low-oxygen (dysoxic) conditions (i.e., minute infaunal suspension-feeding bivalves belonging to Rioclaroa lefevrei, Barbosaia angulata and Ferrazia simplicicarinata, associated with Planolites traces), (b) co-existing chemosymbiontic taxa inhabiting chemically toxic (extreme dysoxic) substrates (i.e., gigantic burrowing bivalves, such as Anhembia froesi, Maackia contorta and Tambaquyra camargoi), and (c) event populations inhabiting (oxic/dysoxic) substrates following short-term bottom disruptions (i.e., Planolites and Thalassionoides traces). In the paleoenvironmental context above, we describe by the first time a unique Permian seep deposit and associated morphologically bizarre, bivalve-dominated fauna. Dark grey mudstones of the Serra Alta Formation cropping out at the km 160.7, of the Castello Branco highway, Porangaba county, State of São Paulo, record two main fossil-rich concretion-bearing horizons. Inside the concretions, large-bodied bivalves (Anhembia froesi, Tambaquyra camargoi and Maackia contorta) are preserved. They are about 10 times larger than those minute bivalves found scattered in laterally equivalent shales of the same unit. Intercalated between the two main concretion-bearing horizons, a cm-thick, tabular, brecciated carbonate layer with microbially-induced sedimentary structures (MISS) is well exposed. In some parts the brecciated carbonate show vertical flame structures formed by injections of mudstones, which are highly bioturbated. The lamination is diffuse and the horizontal traces are all aligned due to the compaction of this unit. Immediately above this, lithified mudstones preserve small domical structures with a slightly depressed center 
(=mounds). Large, horizontal tubes and monospecific concentrations of shells of T. camargoi, mainly preserved as articulated valves, are recorded at the base of these structures. The brecciated carbonate and associated structures (i.e, mounds) are capped by unfossiliferous dark grey mudstones with scattered pyrite crystals. Carbon-isotope $(\delta 13 \mathrm{C})$ values from the (a) brecciated carbonate, (b) bioturbated mudstones, (c) associated carbonate concretions and (d) bivalve shells found inside these are all depleted (negative values $\sim 6,1-7,6 \%$ ). This could indicate that the carbonate may have resulted from the microbial oxidation of methane or other hydrocarbons. The mound-bearing interval of the Serra Alta Formation is recorded $~ 8.7$ meters above the basal contact with the oil-rich Irati Formation. This unit is known by its very high total organic carbon (TOC values up to 17\%) and sulphur contents. Thus, the evidences above may have resulted of seepage active on seafloor. In that places where the sulphide-rich pore water escaped, the seabed was colonized by chemosymbiont bivalves. Contrary to "classic" cold seep deposits that are recorded along plate boundaries, in back-arc basins, our example is tied to organic-rich sediment compaction in an intraplate basin. The species above belong to a high endemic group of pachydomids that were shallow infaunal bivalves (SIB). Hence, they are not related to those "classical" bivalves with living representatives (bathymodiolins, solemyids, thyasirids, lucinids, vesicomyids), which are chemosymbionts. This suggests that these seep bivalves originate of an extreme adaptive radiation and repopulation of anoxic-dysoxic bottoms of the Paraná Basin by SIB species, during the IratiSerra Alta times. 


\section{Índice}

\section{PARTE 1}

1. CONSIDERAÇÕES INICIAIS

1.1. INTRODUÇÃO

1.2. Delimitando O PROBlema

1.2.1. Bases CONCEITUAis E Modelo Evolutivo Vigente

1.2.2. JUSTIFICATIVA

1.2.3. HIPÓTESE DE TRABALHO $\mathbf{0 6}$

1.3. OBJETIVOS

1.4. REFERÊNCIAS BIBLIOGRÁFICAS

PARTE 2

2. MATERIAIS \& MÉTODOS

2.1. GEOLOGIA DA ÁREA DE ESTUdO

2.2. Procedimentos Metodológicos 18

2.3. REFERÊNCIAS BIBLIOGRÁFICAS

\section{PARTE 3}

3. RESULTADOS

3.1. RESUltadOS OBTIDOS 28

\section{PARTE 4}

4. DISCUSSÃO

4.1. DISCUSSÃo SUCINTA

4.1.1. Sobre os BIVALVES Da CRISE ANÓXICA DA FormaÇÃo IRATI (ANEXo 1) $\mathbf{3 1}$

4.1.2. Sobre os ESTUdos REALIZAdos NA FormaÇÃo SERRA Alta (ANEXos 2, 34 $3 \mathrm{E} 4)$

4.2.2.1. Foram os Bivalves da FormaÇão SERRA Alta ElEMENTOS QUimiossimbion 37 TES QUE VIVERAM ASSOCIADOS À Sistema DE EXSUDAÇÃO DE METANO EM UMA BACIA INTRACRATÔNICA?

\section{PARTE 5}

5. CONCLUSÕES

5.1. CONCluSões

5.1.1. PRINCIPAIS CONCLUSÕES RELACIONADAS AOS BIVALVES DA CRISE $\quad \mathbf{5 0}$ ANÓXICA DA FORMAÇÃO IRATI (ANEXO 1)

5.1.2. PRINCIPAIS CONTRIBUÚÇÕES RELACIONADAS DOS ESTUDOS REALIZADOS $\mathbf{5 1}$ NA FORMAÇÃO SERRA ALTA (ANEXOS 2, 3 E 4) 


\section{AneXos}

p.

Anexo 1

Artigo 1: MATOS, S.A., WARREN, L.V., VAREJÃO, F.G., ASSINE, M.L., \& SIMÕ̃S, M.G.

Submetido ao Periódico Palaeogeography Palaeoclimatology Palaeoecology. Permian Endemic Bivalves of the "Irati Anoxic Crisis", Paraná Basin, Brazil: Taphonomical, Paleogeographical and Evolutionary Implications

Anexo 2

Artigo 2: SIMÕES, M.G.; MATOS, S.A.; WARREN, L.V.; ASSINE, M.L.;

RICCOMINI, C. \& BONDIOLI, J.G.

Publicado no Periódico Journal of South American Earth Sciences.

Untold Muddy Tales: The Paleoenvironmental Dynamics of an "Barren" Pelitic Facies in a Shallow Permian Epeiric Sea

\section{Anexo 3}

Artigo 3: Matos, S.A.; WARREN, L.V.; FrANZ, T.F.; AsSINE, M.L.; RiCCOMINI, C.; AlesSANDRETTI, L. \& SimÕES, M.G.

Chemoautotrophic Bivalves From a Late Paleozoic Cold Methane Seep System in an Intraplate Basin: A Case Study From the Brazilian Permian Gondwana

\section{Anexo 4}

Artigo 4: Bondioli, J.G.; MAtos, S.A.; WARREN, L.V.; Assine, M.L.; RICCOMINI, C. \& SIMÕES, M.G.

Publicado no periódico Lethaia (http://dx.doi.org/10.1111/let.12124)

The Interplay Between Event and Background Sedimentation and the Origin of Fossil-rich Carbonate Concretions: a Case Study in Permian Rocks of the Paraná Basin, Brazil 


\section{ÍNDICE DE FIGURAS}

Figura 1. Distribuição vertical das assembleias de bivalves do p. Grupo Passa Dois, com destaque para o intervalo basal do Membro Serrinha onde uma possível nova biozona está presente. Arcabouço bioestratigráfico de Rohn (1994). Retirado de Simões et al. (2015).

Figura 2. Representação da composição, diversidade e modo de vida das faunas de bivalves encontradas nas Formações Teresina e Rio do Rasto, Grupo Passa Dois, Bacia do Paraná. Note as profundas alterações da malacofauna ao longo do processo de continentalização da bacia. Retirada de Simões et al. (2015). 


\title{
ÍNDICE DE FIGURAS DOS ANEXOS
}

\begin{abstract}
ARTIGO 1
Figure 1- Stratigraphic distribution of the Permian bivalve assemblages, Passa Dois Group, Paraná Basin, Brazil. Note (*) the new assemblage at the basal portion of the succession. Modified of Rohn $(1994,2007)$.

Figure 2- Stratigraphic distribution of bivalve shells within Irati Formation in representative boreholes in the northern part of the State of Paraná. Note that the bivalves are confined to the basal portion of the unit. Shell beds at the uppermost portion of the Irati Formation are made of crustacean remains (see Matos et al., 2013, for details). Shell-rich pavements or shell beds are in red. Modified from Rohn (2007) and Holz et al. (2010a).
\end{abstract} p.

Figure 3- Paleogeographic map of the central Gondwana region (South America, Namibia and South Africa), showing the main flooded areas during the Irati anoxic event. Modified of Faure and Cole (1999).

Figure 4- A: Location of the Permian strata of the Paraná Basin, at the State of Paraná, southern Brazil. B: Geologic map with the distribution of the late Paleozoic rocks in the study area, showing the location of the columnar sections. C: Schematic lithostratigraphic column of the Permian Guatá and Passa Dois Groups. Source of data: Mineropar (2006).

Figure 5- Columnar sections of the basal portion of the Irati Formation, Taquaral Member, in the studied area. Note 325 the progradational architecture of the succession. Abbreviations: $\mathrm{C}=\mathrm{Clay} ; \mathrm{S}=\mathrm{Silt} ; \mathrm{FS}=$ Fine sand; MS = Medium; 326 sand; CS = Coarse sand; $\mathrm{G}=$ Granule.

Figure 6- The Irati Formation in an abandoned quarry near Irati-SP (Section A) (see Table 1). A: Columnar section showing the bivalve rich interval at the Taquaral Member; B: Overview of the outcrop where Section A was acquired; C: Detail of the bivalve-rich level; D: Laminated organic-rich shale from the basal portion of the unit with numerous mm thick, laterally continuous shell pavements. E: Close-up view of a $\mathrm{cm}$ thick slab of organic-rich shale with several $\mathrm{mm}$ thick shell pavements (white arrows). Abbreviations: $\mathrm{C}=\mathrm{Clay}$; $\mathrm{S}=$ Silt; $\mathrm{FS}=$ Fine sand; $\mathrm{MS}=$ Medium sand; $\mathrm{CS}=$ Coarse sand; $\mathrm{G}=$ Granule. Scales $=1 \mathrm{~cm}$.

Figure 7- The Irati Formation in an abandoned quarry near Irati-SP (Section B) (see Table 1). A: Stratigraphic column showing the bivalverich interval from the basal portion of this unit (=Taquaral Member); B: Overview of the outcrop where Section A was acquired; C: Pavement close-up, bedding plane view of the shell concentration. Note the abundance of complete disarticulated shells; D: Pavement close-up, bedding plane view of the shell concentration. Note the abundance of fragmented specimens; E: Section view of the same sample in D. Scales $=1 \mathrm{~cm}$.

Figure 8- Bivalve-rich pavements in basal portion of the Irati Formation 
(Quarry A). Note the variable degree of shell covering (A, B, D) from dense (surface totally covered by valves) to sparse. A: Sample showing high density of complete, convex-up orientated shells; B: Similar to A, but note the high amount of minute shells remains; C: Detailed vertical distribution of the studied shell pavements and associated rocks, Quarry A, see Table 1; D: Relatively sparse covering of whole convex-up shells; E: Plan view of a fissile and almost barren, bivalve mudstone with small, disperse and disarticulated, chaotically oriented bivalve shells. This fossil-poor interval is overlain by organic-rich shales with shell pavements.

Figure 9- Figure 9- Shell-pavements from fallen slabs DZP-19014 (A), DZP-19010 (B), DZP-19019 $\quad$ (C) showing the orientation of disarticulated shells on bedding planes of organic-rich shales of the Irati Formation. Rose diagram showing orientation of the shells; proportions of convex-up or -down valves and shell size sorting are exposed on the right.

Figure 10- Permian bivalves of the Irati Formation. A: Silicified shell of Runnegariella fragilis, right valve, interior view, for comparisons, DZP19234, Teresina Formation. B: Drawing of the same specimen. C-F: External and internal molds of the Runnegariella sp., Irati Formation (DZP-19202; DZP-19226; DZP-19217; DZP-19174). G: Plesiocyprinella carinata, internal mold, left valve, for comparisons, Corumbataí Formation, DZP-2289. H-I: Internal molds, right valves of Plesiocyprinella sp., Irati Formation Formation (DZP-19191; DZP19168). Graphic scale: A-F; H-I=3mm, G=10 mm.

Figure 11- A: Schematic diagram showing the deposition of the bivalve-rich pavements in distal facies of the Irati Formation. The shells were transported by storm flows from shallow water habitats, where thrived a bivalve fauna in "Irati Sea" (B). Posteriorly, the shells were sorted and oriented by long-lasting shelf currents. 


\title{
ÍNDICE DE FIGURAS DOS ANEXOS
}

\begin{abstract}
ARTIGO 2
Figure 1- A. Location map of the study area, near to the city of Porangaba, State of São Paulo; B. Google Earth image (Date: 25/02/2016; Satellite sensor: Landsat) showing the outcrops sampled along the highway cuts, SP-280 (Castello Branco highway).

Figure 2- Section of the basal part of the Serra Alta Formation, km 160.7, SP-280 (Castello Branco highway), State of São Paulo.

Figure 3- A-B. Dark grey siltstones of the basal portion of the Serra Alta Formation. C-F. Detail of the two main carbonate concretionbearing horizons; C. Large concretions, which are found in the lowermost carbonate concretion-bearing horizon; D. Small carbonate concretion found in the upper concretion-rich horizon; E-F. Bivalve shells (Tambaquyra camargoi) within a carbonate concretion; G. Clastic dike cutting across the muddy rock (white arrows); $\mathrm{H}$. A clastic dike (white arrows) in detail.
\end{abstract}

Figure 4- A. Decimeter-thick intercalation of fine grained sandstones with low angle cross-stratification. Note the sharp basal contact; B. Bioturbated silty sandstone intercalated between laminated siltstones. Note the presence of large burrows (black arrows) at the base of the layer.

Figure 5- A $\sim 20-\mathrm{cm}$-thick brecciated limestone with microbial lamination at the top. A. Thalassinoides burrows at the base of the limestone. B. Cross-section of the same sample. Note the lamination at the top C. Planolites isp. from the same bedding plane as in A.

Figure 6- Phosphate-rich layer at the top of the section; A. Plan-view, showing phosphate nodules of various sizes (sand to pebble). B. Note the sharp and erosional base. C. Phosphate nodules of various sizes associated with large $(\mathrm{cm})$ bone remains (white arrow). D. Polished, thin-section showing the complex nature of the phosphate-rich layer. Note the presence of small, bone (I) and shell fragments (II), and intraclasts (III). Phosphate nodules of distinct sizes (IV) are also visible as well as nodules with different nuclei $(\mathrm{V})$.

Figure 7- A. Siltstone from the basal part of the Serra Alta Formation where small bivalve shells are disperse (see below); Note in B, how a dysoxic event allowed low-oxygen adapted taxa to inhabit the uppermost layer of the substrate (modified from Berrocoso et al., 2008). C-E. Examples of small bivalves found in the laminated siltstone. C. Articulated Houdhausiella elongata specimen in butterfly posture (DZP-2282); D. Disarticulated valve of Barbosaia angulata (DZP-2267); E. Articulated undetermined bivalve (DZP-2277). SWI=Substrate-water interface.

p. 109 
Figure 8- A. Dark grey siltstones with carbonate concretions;B. 116 Extremely dysoxic bottoms colonized by large chemosymbiotic bivalves (modified from Berrocoso et al., 2008). C-E. Bivalves found within carbonate concretions. C. Tambaquyra camargoi (DZP-2896). D. Cross-section view of two articulated bivalves within a concretion. E. Disarticulated specimen of Anhembia froesi (DZP-2889). SWI= Substrate-water interface. 


\section{ÍNDICE DE FIGURAS DOS ANEXOS}

\section{ARTIGO 3}

Figure 1- Figure 1- Location map of the study area, Porangaba p. County, State of São Paulo. A- Index map showing the Paraná Basin; B- Map presenting the location of the main investigated outcrops of the Serra Alta Formation; C and D- Aerial images showing the precise location of the exposures of the Irati and Serra Alta formations at the river margins (outcrop 1) and road cuts (outcrops 2-4). Scales: 100m.

Figure 2- Sedimentary succession of the Irati and Serra Alta Formations. A- Composite section of both units, showing the stratigraphic position of each outcrop (1 to 4). B- Simplified chart of the Permian succession of the Paraná Basin in which the examined interval of Serra Alta Formation is indicated.

Figure 3- Summary chart showing the lithotypes, and associated sedimentary, paleontological, and taphonomical features of the mound interval of the Serra Alta Formation.

Figure 4- Exposures of the Irati and Serra Alta formations, along the Aleluia creek, Porangaba County, State of São Paulo. ABlack shales with petroleum odor, underlying Irati Formation. BFine-grained sandstones of the basal part of the Serra Alta Formation. C- Silex chert nodules in shale. D- Smal mesossaur ribs in a limestone bed immediately below the black shales in E. E- Close-up of the well-laminated, pyro-bituminous dark shales of the Irati Formation. F- Mudstones of the basal part of the Serra Alta Formation, which locally overlie the black shales of the oilbearing Irati Formation. Scales in C, D and E: $5 \mathrm{~cm}$.

Figure 5- Carbonate beds and concretions of the Serra Alta Formation. A- Mudstones of the basal part of the Serra Alta Formation showing the main concretion-bearing horizons, and the brecciated carbonate bed (arrowed). B- Clastic dike ending just at the base of a carbonate concretion. C-A calcite dike just ending at the base of the brecciated carbonate bed.

Figure 6- General taphonomic, paleontologic, and sedimentologic features of the brecciated carbonate. A- Sectionview of an $86-\mathrm{cm}$ long slab showing a well preserved low relief mound at right. B- Plan-view of the same slab. C- Section of the brecciated carbonate where the flame structures are visible. DDetail of a flame structure. E- A monospecific assemblage of Tambaquyra camargoi at the base of mound. F- Drawings of the shells in E. G- Close-up of an external mold of a right valve of Tambaquyra camargoi. H- In situ closed valve of this bivalve 
species.

Figure 7- Plan-views of the small domes and associated structures at the top of the brecciated carbonate bed, Serra Alta Formation. A- Bedding plane showing various small domes. BDetail of two low-relief domes in A. C- Isolated dome. DCarbonate siltstones intruded (flame structure) in the brecciated carbonate bed (see also Fig. 6). E- Detail of D. Scale bar in B, C and $\mathrm{E}: 5 \mathrm{~cm}$.

Figure 8- A, B, E, F. Anhembia froesi A- lateral view, left valve, showing the large and deeply impressed anterior adductor and retractor muscle scars (DZP-2889). B- Same specimen, detail of the anterior muscle scars. E- Internal mold of the left valve with deeply impressed adductor muscle scars (DZP-2890). F- Inferred mode of life of Anhembia froesi. C-D. Anhembia gigantea $\mathrm{C}$ - Internal mold of the left valve, note the welldeveloped anterior prong (=rostrum). D- Same specimen showing the adductor muscle scar and rostrum. apr- anterior protractor muscle scar; aa- anterior adductor muscle scar, and pa- posterior adductor muscle scar. Little flames: hydrocarbons flow. Scale bar: $1 \mathrm{~cm}$.

Figure 9- A-D Tambaquyra camargoi. A- Lateral view, internal mold, right valve of a large specimen (DZP-2250). B- Inferred mode of life of Tambaquyra camargoi. C- Detail of the same specimen in A, note the large, elongated and deeply impressed anterior adductor muscle scar, as well as other muscle scars. DComposite mold, right valve, showing the ornamentation. aaccessory muscle scar; apr- anterior protractor muscle scar, and aa- anterior adductor muscle scar. Little flames: hydrocarbons flow. Scale bar: $1 \mathrm{~cm}$.

Figure 10- A-F Maackia contorta. A-D Specimen DZP-18996 showing the articulated valves. A- Dorsal view, showing the highly convex left valve, and the flat right one. B- Lateral view of the flat right valve. C- Lateral view of the left valve with a well-developed posterior umbonal carina. D- Ventral view showing the twisted commissure. E- Internal mold of the left valve, showing the large, elongate anterior muscle scar (DZP18997). F- Inferred mode of life of Maackia contorta. Note the flat valve to the top and the lifted posterior end of the shell. aaanterior adductor muscle scar. Little flames: hydrocarbons flow. Scale bar: $1 \mathrm{~cm}$.

Figure 11- Idealized biofacies model for the Late Paleozoic units 
of the Passa Dois Group, showing the lateral variation in bivalve assemblages and amounts of dissolved bottom oxygen. The Teresina and Irati formations are ending members of this model. The chemosymbiotic bivalves of the Serra Alta Formation are found in the exaerobic or lower dysaerobic biofacies of the standart low-oxygen biofacies model of Savrda and Bottjer (1991), and Wignall and Hallman (1991), respectively. See also figure 12 for a comparison with various low-oxygen biofacies models from Paleozoic, Mesozoic and Modern oceans.

Figure 12- Comparison of various low-oxygen biofacies models, including the standard low-oxygen model (top row), with upwelling-variants (Modern and Cretaceous) and the model recognized here for a Permian epeiric sea. Based on EdelmanFurstenberg and Kidwell (2015).

Figure 13- Simplified, schematic diagram of the carbonate mounds and associated methane/oil seep system and fauna of the Permian Irati and Serra Alta formations, Paraná Basin, Brazil.

Figure 14- Diagrams illustrating the formation of the brecciated carbonate and associated in situ bivalve shell concentration. Based on Nobuhara (2003). 


\title{
ÍNDICE DE FIGURAS DOS ANEXOS
}

\begin{abstract}
ARTIGO 4
Figure 1- A, sketch showing the main sample locations, and taphonomic and trace fossil data for the carbonate concretions and host mudstones. Beds 1 and 2 denote the intervals where concretions are abundant. B, detail of a carbonate concretion and associated host mudstone (Bed 1). Drawing inspired in El Albani et al. (2001).

Figure 2- A, location map of the study area, Porangaba Region, State of São Paulo. B, geological map showing the Late Palaeozoic and Mesozoic units in the outcrop belt.

Figure 3- A, Composed stratigraphical section summarizing the stratigraphic information of the Serra Alta Formation from two outcrops along the kilometres 160.7-161.7, SP-280 highway, Porangaba County (coordinates S23 ${ }^{\circ} 14023.69^{\prime \prime} / \mathrm{W} 48^{\circ} 06032.49^{\prime \prime}$; $\left.\mathrm{S} 23^{\circ} 14019.420 / \mathrm{W} 48^{\circ} 07005.520\right)$. Note the beds (1 and 2$)$ where carbonate concretions are common. Rare, isolate concretions also recorded at the base of the section and above the concretion-bearing Bed 2. B , carbonate concretions size measurements (maximum length parallel to bedding). Note the difference in sizes among concretions in Beds 1 and 2, respectively.
\end{abstract}

Figure 4- Well-preserved bivalve shells encased in carbonate concretions, and massive mudstones interbedded in laminated siltstones (see also Fig. 3), Permian Serra Alta Formation. A, large shell of Tambaquyra camargoi, lateral view, Bed 1 (DZP-2250). B, the same specimen in the original carbonate concretion. C, Holdhausiella elongata, lateral view, Bed 1 (DZP-2889). D, the same specimen showing a well preserved anterior adductor muscle scar. E-G, a small bivalve shells found in massive mudstones, below Bed 1 (see Fig. 3). E, Maackia contorta, lateral view. F, Rioclaroa lefevrei, dorsal view of both valves. G, a small undetermined bivalve shell, lateral view.

Figure 5- A, B, small carbonate concretions, Bed 2 (arrow). C, large carbonate concretion, Bed 1. D, detail of the same concretion, note the enhanced compaction of the surrounding siltstones and mudstones, which are 'wrapping around' the concretion. E, panoramic view (road cut) of the Serra Alta Formation cropping out at the kilometre 160.7, SP-280 highway, Porangaba County, State of São Paulo. Note the concretion-bearing interval (Bed 1).

Figure 6- A, centimetre-thick, fine-grained sandstone with low-angle cross-stratification intercalated in mudstones. B, centimetre-thick, tabular limestone intercalated between concretion-bearing Beds 1 and 2, outcrop 1. C, slabbed limestone bed showing abundant cracks at the base (DZP-17019) and laminations at the top. D, plan view of the base of the same limestone with horizontal traces. E, slabbed phosphaticrich bed, plan view. Note the phosphatic nodules and the differences in shape and grain sizes. F, the same sample (section), showing a sharp and erosive base. G, panoramic view (road cut) of the Serra Alta

p. 
Formation cropping out at the kilometre 161.7, SP-280 highway, Porangaba County, State of São Paulo. The concretion-bearing intervals (Beds 1 and 2) are indicated by arrows. Note the tabular, cracked limestone bed immediately below Bed 2 .

Figure 7- A, concretion-bearing interval (Bed 1) succeeded by a centimetre thick, massive mudstone layer (arrow). B, loosely packed, disarticulated bivalve shells (arrow) at the top of a small concretion (Bed 2). Note the concave-upward shells. C, D, closed articulated bivalve shells with distinct infillings. Note the coarse-grained infilling in D (Bed 2). E, comminuted shell debris with sharp edges. Note the associated horizontal traces. F, abundant, closed articulated and deformed bivalve shells (Bed 2). G, large bivalve shells disperse at the base of a concretion (Bed 2). Note the nested, concave-up oriented shells. $\mathrm{H}$, bivalve-rich concretion with disperse, concave-upward valves. Note the vertical differences in grain sizes, shell packing and trace fossil density.

Figure 8- General model for preservation of bivalve-rich layers in mudstones (concretion-bearing Beds 1 and 2), Permian Serra Alta Formation, Brazil. Main steps based on Brett et al. (2012a,b). A, preburial (biostratinomic) phase showing the influx of fine-grained terrigenous sediments, also including resuspended tiny shells, muds and silts. B, distal substrate (below storm wave base, SWB) reached by bottom-flowing mudflows, entraining the infauna. $\mathrm{C}$, rapid buried bivalve fauna mixed with other shells in an event-generated mudstone bed. D, post-burial conditions during extended interval of low sedimentation rate, and incipient cementation within the sediments, and redistribution of dissolved calcium carbonate from various sources. Conditions of elevated $\mathrm{pH}$ favour calcium carbonate precipitation forming concretionary bodies. E, lens-shaped concretion is generated in association with compaction. Due to the low sedimentation rates, the newly formed carbonate concretions will stay in the zone of sulphate reduction (SRZ) for prolonged time, favouring their growth. 


\section{ÍNDICE DE TABELAS DOS ANEXOS}

\section{ARTIGO 1}

p.

Table 1- Locations and conditions of the bivalve-rich quarries of the Irati Formation, Taquaral Member, near the city of Irati-PR (UTM Zone J). 


\section{ÍNDICE DE TABELAS DOS ANEXOS}

ARTIGO 3

Table 1- $\delta^{13} \mathrm{C}$ and $\delta^{18} \mathrm{O}$ values of carbonates of the mound $\mathbf{1 3 8}$ interval of the Serra Alta Formation. 


\section{ÍNDICE DE TABELAS DOS ANEXOS \\ ARTIGO 4}

Table 1- Main sizes of the measured carbonate concretions, Serra Alta Formation.

Table 2- Structure of quantitative data used; all numbers represent counts.

Table 3- Absolute and relative abundances of bivalve species in concretions and mudstones.

Table 4- Taphonomy of bivalve shells enclosed in concretions and mudstones; all numbers represent counts. 


\section{PARTE 1}

1. CONSIDERAÇÕES INICIAIS 


\subsection{INTRODUÇÃO}

Fácies sedimentares caracterizadas pela deposição de sedimentos siliciclásticos, em condições de baixa energia, circulação restrita de água e, consequentemente, com variação nas taxas de oxigenação de fundo, são comuns no registro Fanerozoico, especialmente no Paleozoico e Mesozoico (Sageman et al., 1991; Boyer \& Droser, 2011). São particularmente importantes nas sucessões marinhas transgressivas, especialmente as geradas em bacias intracratônicas (Kauffman, 1984; Oschmann, 1994; Holz et al., 2010). Tais depósitos podem estar associados a condições ambientais de baixa ou alta produtividade primária (EdelmanFurstenberg \& Kidwell, 2015). Sucessões sedimentares associadas a essas condições são marcadas, muitas vezes, por espessos pacotes de folhelhos ou argilitos/siltitos maciços, com ausência ou reduzida ocorrência de fósseis de macroinvertebrados bentônicos, traços fósseis ou, até mesmo, microfósseis carbonáticos. Assim sendo, à primeira vista, constituem sucessões monótonas, aparentemente afossilíferas, as quais são pouco exploradas em termos de estudos paleoecológicos e paleoambientais (Sageman et al., 1991).

No Permiano da Bacia do Paraná, a sucessão representada pelas formações Irati e Serra Alta contém diversos depósitos que se enquadram na descrição acima (Schneider et al., 1974; Araújo, 2001; Araújo et al., 2001; Holz et al., 2010; Warren et al., 2015). Na presente tese, esses depósitos foram explorados no que tange ao seu conteúdo macrofaunístico, tafonomia, sedimentologia e, em menor grau, geoquímica, com o intuito de melhor esclarecer a gênese de certas ocorrências fossilíferas, bem como discutir suas implicações paleoambientais. Os dados apresentados e discutidos mostram não apenas o potencial dos métodos empregados, mas quão complexa pode ser a origem dessas ocorrências, em termos paleoambientais. Além disso, demonstram como fácies sedimentares tidas como monótonas, em termos de suas feições sedimentológicas e estratigráficas, podem prover relevante quantidade de dados para as reconstruções paleoambientais e paleogeográficas.

\subsection{Delimitando o Problema}

Na literatura especializada, a malacofauna endêmica do Permiano da Bacia do Paraná (Mendes, 1952; Runnegar \& Newell, 1971; Simões et al., 1997) é conhecida como contendo os exemplos conhecidos mais antigos de evolução in situ de membros da Classe Bivalvia (Linneus, 1758), em bacias sedimentares interiores (Wesselingh, 2007). De fato, como destacam Runnegar \& Newell (1971), os moluscos do Grupo Passa Dois representam 
um episódio importante na história evolutiva dos moluscos bivalves (veja síntese em Simões et al., 1998). A evolução desses organismos se desenvolveu de maneira rápida, em condições de extremo isolamento geográfico, variações do nível do mar e alterações paleoambientais que ocorreram ao longo do progressivo processo de continentalização da Bacia do Paraná, no Permiano (Beurlen, 1954; Runnegar \& Newell, 1971; Simões et al., 1998).

Os bivalves do Grupo Passa Dois são conhecidos desde 1918, a partir do estudo de Holdhaus (1918). Esses fósseis, sabemos agora, ocorrem nas formações Irati, Serra Alta, Teresina/Corumbataí e Rio do Rasto, distribuídos nas assembleias de Anhembia froesi, Pinzonella illusa, Pinzonella neotropica, Terraia curvata, Leinzia similis e Paleomutela? platinensis (vide Fig. 1). As pesquisas sobre esses bivalves podem ser inseridas em diferentes fases, com muitos estudos nas décadas de 1940-1950 e, estudos esporádicos nos anos 60, 70 e 80 (veja Simões \& Fittipaldi, 1987, 1992; Salvador \& Simone, 2010). No entanto, desde os anos 1990, novas pesquisas vêm sendo realizadas no âmbito da sistemática (Mezzalira et al., 1990; Simões \& Anelli, 1995; Simões \& Mello, 1996; Simões et al., 1997, 2000a, 2015), paleoecologia (Simões et al., 1998; Kowalewski et al., 2000; Ghilardi \& Simões, 2002), evolução (Simões et al., 1998) e tafonomia da malacofauna (Simões et al., 1996; Simões \& Kowalewski, 1998; Simões et al., 2000b; Simões \& Torello, 2003). A despeito dos artigos de Salvador \& Simone (2009, 2010), Neves et al. (2010, 2011) e Anelli et al. (2010), tratando de técnicas de preparação, do histórico das pesquisas e da tafonomia da fauna, desde as publicações de M.G. Simões e sua equipe, na década de 1990 e início dos anos 2000, pouco tem sido feito com relação aos estudos dos bivalves do Grupo Passa Dois. 


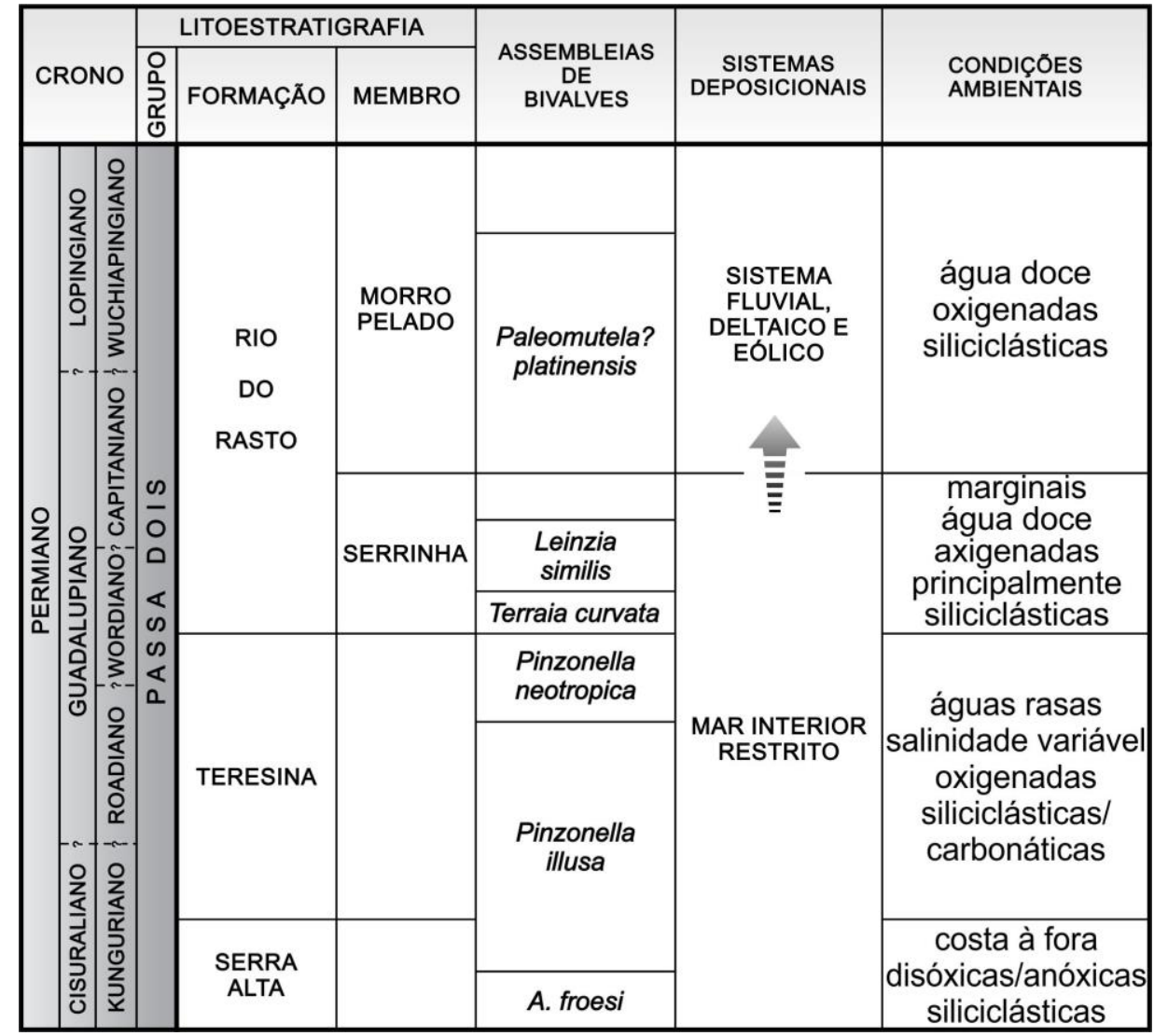

Figura 1. Distribuição vertical das assembleias de bivalves do Grupo Passa Dois, com destaque para o intervalo basal do Membro Serrinha onde uma possível nova biozona está presente. Arcabouço bioestratigráfico de Rohn (1994). Retirado de Simões et al. (2015).

No contexto acima, é notório que historicamente as pesquisas tenham se concentrado nas ocorrências da parte média/superior das formações Corumbataí e Teresina, onde os bivalves estão, em geral, silicificados e, muitas vezes, muito bem preservados. De fato, na clássica revisão da fauna realizada por Runnegar \& Newell (1971) é notável a ênfase à descrição dos fósseis justamente do intervalo onde aparecem melhor preservados (i.e., assembleias de Pinzonella illusa e Pinzonella neotropica). Entretanto, a despeito dos esforços de Maranhão (1986, 1995) e Simões et al. (2000a) pouco é sabido sobre a sistemática, tafonomia e paleoecologia dos bivalves da Formação Serra Alta (senso Warren et al., 2015). O mesmo ocorre com relação aos raros registros de bivalves encontrados na Formação Irati (Beurlen, 1957; Kazubek \& Simões, 2002, 2003a, b; Rohn et al., 2003; Lages, 2004). O estudo desses fósseis é considerado imprescindível para a melhor compreensão da evolução e distribuição vertical das assembleias de bivalves do Grupo Passa Dois, com óbvias implicações para a paleoecologia e contexto estratigráfico/paleogeográfico do intervalo em que ocorrem. 


\subsubsection{Bases Conceituais E Modelo Evolutivo Vigente}

Parece haver consenso na literatura que os bivalves do Grupo Passa Dois evoluíram a partir de ancestrais marinhos (Runnegar \& Newell, 1971; Simões, 1992; Simões et al., 1997, 1998), especialmente dos Anomalodesmata e Veneroida, presentes em rochas do Grupo Tubarão, subjacente, e de outras unidades coevas do Gondwana (Runnegar \& Newell, 1971; Simões et al., 1998). Entretanto, apesar de raras ocorrências citadas em alguns resumos e teses (Beurlen, 1957; Kazubek \& Simões, 2002, 2003a, b; Rohn et al., 2003; Lages, 2004), até a presente tese não foram oficialmente descritas faunas de bivalves na Formação Irati, em posição intermediária entre as ocorrências seguramente marinhas das formações Taciba (Neves et al., 2014; Taboada et al., 2016), Rio Bonito (Rocha-Campos, 1970a, b) e Palermo (Simões, 1992, 2000; Simões \& Anelli, 2010) e aquelas das formações Serra Alta, Teresina e Corumbataí (Mendes, 1952; Runnegar \& Newell, 1971; Maranhão, 1986; Simões et al., 1997, 1998). A hipótese mais aceita é a de que, durante o intervalo anóxico representado pelos folhelhos negros da Formação Irati a fauna ocupou as margens da bacia (cujo registro hoje está parcialmente erodido), onde condições de águas mais oxigenadas poderiam ter prevalecido (veja Runnegar \& Newell, 1971). Contudo, a retomada de condições mais oxigenadas durante a deposição da Formação Serra Alta e, certamente, da parte média/superior da Formação Teresina é acompanhada pelo aparecimento de uma diversificada fauna endêmica, cuja diversidade e abundância de certos táxons (e.g., Pinzonella illusa) são admiráveis.

\subsubsection{JUSTIFICATIVA}

Atualmente existem dois grandes conjuntos de dados ou coleções científicas contendo bivalves da Formação Serra Alta, ainda pouco exploradas, ou seja, (a) a Coleção Científica do Instituto Geológico da Secretaria do Meio Ambiente do Estado de São Paulo e (b) do Laboratório de Paleozoologia Evolutiva do Departamento de Zoologia do IBB/UNESP.

A coleção de bivalves da Formação Serra Alta do Laboratório de Paleozoologia Evolutiva do Departamento de Zoologia do IBB/UNESP foi coletada, maiormente, no final da década de 1990, no âmbito do projeto (FAPESP 96/09708-9), quando foi notado que nas faces abandonadas de pedreiras de extração de calcário ao longo da rodovia Fausto Santomauro (SP-127), no Distrito de Assistência, município de Rio Claro, SP, o contato entre os folhelhos pirobetuminosos da Formação Irati e os argilitos e siltitos arroxeados da base da Formação Corumbataí podia ser facilmente observado. Em especial, a última intercalação rítmica de 
dolomitos e folhelhos pirobetuminosos que são recobertos por pelitos arroxeados, com finas intercalações de arenito (Formação Corumbataí) estavam expostas (Simões et al., 2000c). Nesses afloramentos a ocorrência de bivalve se dá a cinco metros do topo da Formação Irati (ou Fm. Assistência). Em adição, nesta coleção, estão ainda depositados espécimes provenientes da Rodovia Castello Branco, km 160,7 (SP-280). Onde pode ser observada uma sucessão de pelitos escuros intercalados a níveis bem marcados de concreções carbonáticas. Estas ocorrências também estão a poucos metros da Formação Irati (Teixeira, 2014).

Finalmente, foram re-localizadas ocorrências de conchas de bivalves formando inúmeros pavimentos nos folhelhos negros da Formação Irati, na região homônima, no Estado do Paraná, onde tais horizontes fossilíferos podem ser correlacionados por dezenas de quilômetros (vide anexo 1). Essas ocorrências foram indicadas por Simões \& Kazubek (2002, 2003a, b) em resumos em eventos científicos, no começo dos anos 2000. Porém, nunca haviam sido estudadas em detalhe. As ocorrências de bivalves na Formação Irati são raras e esparsas na literatura (Beurlen, 1957; Kazubek \& Simões, 2002, 2003a, b; Rohn et al., 2003; Lages, 2004), a despeito da sua grande importância para o melhor entendimento da evolução da malacofauna endêmica do Grupo Passa Dois. Dessa forma, a re-localização destes afloramentos permitiu o melhor entendimento das condições paleoambientais durante a crise anóxica dos "tempos Irati", assim como dos processos tafonômicos e sedimentológicos responsáveis pela produção de concentrações densas de conchas em ambientes lamosos de offshore (costa à fora).

Concluindo, portanto, o estudo dos bivalves das porções basais do Grupo Passa Dois no Estado de São Paulo e Paraná, com base na revisão de coleções pré-existentes e dados inéditos oriundos de novas coletas, foram relevantes por fornecerem (1) dados adicionais para o entendimento do quadro evolutivo da malacofauna endêmica do Grupo Passa Dois, e para a solução dos problemas ainda pendentes quanto aos (2) ambientes deposicionais das formações Irati e Serra Alta.

\subsubsection{HipóteSE DE TRABALHO}

A presente tese esta fundamentada na hipótese de que espessas sucessões de rochas sedimentares, caracterizadas por folhelhos e argilitos, geradas por decantação de finos, em condições de costa à fora (offshore), abaixo do nível de base de ondas de tempestades, as quais são à primeira vista, monótonas e afossilíferas, podem preservar quantidade apreciável de informações paleoambientais e paleoecológicas, desde que investigadas de forma 
integrada, em escala centimétrica de detalhe. Nesse sentido, a sucessão representada pelas formações Irati e Serra Alta, Grupo Passa Dois da Bacia do Paraná oferece oportunidade única de estudo. Em contraposição as bem estudadas ocorrências fossilíferas de depósitos coevos gerados em condições de águas rasas (i.e., Formação Teresina), pouco é sabido sobre as faunas de bivalves das formações Irati e Serra Alta e seu significado paleoambiental (Fig. 2). Dessa forma, esse estudo objetivou obter dados para o esclarecimento das questões relativas à tafonomia, composição taxonômica, caráter paleoecológico e distribuição vertical das faunas de bivalves das duas unidades litoestratigráficas acima mencionadas. De modo mais amplo, visou ampliar o conhecimento sobre o significado paleoambiental dos bivalves que se desenvolveram em fácies sedimentares deficientes em oxigênio, em mar epicontinental. Adicionalmente, os dados obtidos permitiram melhor compreensão da evolução da famosa malacofauna endêmica do Grupo Passa Dois.

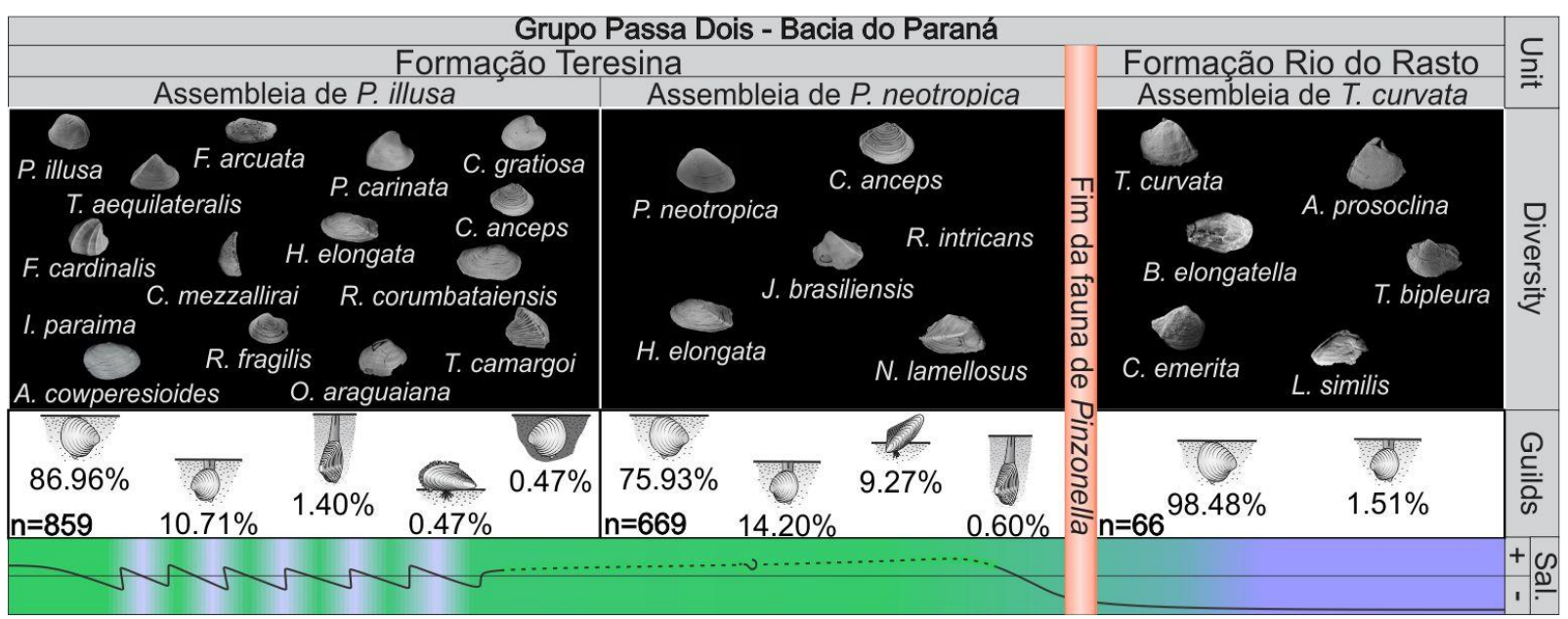

Figura 2. Representação da composição, diversidade e modo de vida das faunas de bivalves encontradas nas Formações Teresina e Rio do Rasto, Grupo Passa Dois, Bacia do Paraná. Note as profundas alterações da malacofauna ao longo do processo de continentalização da bacia. Retirada de Simões et al. (2015). Qual teria sido a composição e a diversidade da fauna de bivalves nos tempos Irati e Serra Alta que precederam às formações Teresina e Rio do Rasto?

\subsection{OBJETIVOS}

Tendo em vista que ocorrências inéditas estão disponíveis, bem como coleções abrangentes ainda pouco exploradas, estudos tafonômicos, paleoecológicos e a identificação dos elementos da malacofauna basal do Grupo Passa Dois (formações Irati e Serra Alta) são altamente desejáveis, a fim de possibilitar discussões mais aprofundadas sobre a evolução da fauna endêmica dos bivalves do Permiano da Bacia do Paraná. Esses dados possuem também óbvias implicações bioestratigráficas e geocronológicas. 
No contexto acima, esse projeto tem como objetivo geral determinar a história tafonômica das ocorrências de bivalves nas formações Irati e Serra Alta e interpretar o significado paleoecológico e paleoambiental dos bivalves encontrados na porção basal do Grupo Passa Dois. Esse objetivo foi cumprido a partir da realização dos seguintes objetivos específicos:

a- Estudo tafonômico dos bivalves das formações Irati e Serra Alta, como base para interpretações paleoecológicas e paleoambientais;

b- Correlação dos dados paleontológicos, estratigráficos e sedimentológicos com a finalidade de entender a dinâmica sedimentar de sucessões marcadas por folhelhos negros ou argilitos gerados em condições de anoxia ou baixas taxas de oxigenação de fundo;

c- Descrição e interpretação de um possível sistema de exsudações de metano na Formação Serra Alta com base na ocorrência de bivalves possivelmente quimiossimbiontes e na presença de estruturas e litologias geralmente geradas por este tipo de sistema.

\subsection{REFERÊNCIAS BIBLIOGRÁFICAS}

ANELLI, L.E.; SIMÕES, M.G. \& DAVID, J.M. (2010) A new Permian bivalve (Megadesmidae, Plesiocyprinellinae) from the Serrinha Member, Rio do Rasto Formation, Paraná Basin, Brazil. Revista do Instituto de Geociências - USP, Série científica, 10(2): 13-21.

ARAÚJO, L.M., (2001) Análise da expressão estratigráfica dos parâmetros de geoquímica orgânica nas Seqüências Deposicionais Irati. Tese de Doutorado. Universidade Federal do Rio Grande do Sul, 307pp.

ARAÚJO, L.M., RODRIGUES, R. \& SCHERER, C.M.S. (2001) Sequências deposicionais Irati: arcabouço químio-estratigráfico e inferências paleoambientais. Ciência-TécnicaPetróleo, 20: 193-202.

BEURLEN, K. (1954) As faunas de lamelibrânquios do sistema Gonduwânico no Paraná. In:

LANGE, F. W. (Ed.), Paleontologia do Paraná, Volume Comemorativo do $10^{\circ}$ Centenário do Estado do Paraná, Curitiba, Brasil, p. 107-136.

BEURLEN, K. (1957) Um lamelibrânquio do Folhelho Irati de São Mateus do Sul, Estado do Paraná. Notas Preliminares e Estudos. Divisão de Geologia e Mineralogia 98: 1-5. 
BOYER, D.L. \& DROSER, M.L., (2011) A combined trace and body fossil approach reveals high resolution record of oxygen fluctuations in Devonian seas. Palaios, 26: 500-508.

EDELMAN-FURSTENBERG, Y. \& KIDWELL, S.M. (2015) Chemosymbiont-dominated seafloor communities in modern and Cretaceous upwelling systems support a new, highproductivity variant of standard low-oxygen models. Geology, 43: 975-978.

GHILARDI, R.P. (1999) Paleoautoecologia dos bivalves do Grupo Passa Dois (Neopermiano) no Estado de São Paulo: bivalves fósseis como indicadores da dinâmica sedimentar. Dissertação de Mestrado. Instituto de Geociências, USP 160pp.

GHILARDI, R.P. \& SIMOES, M. G. (1997) Muscle scars of a few Permian bivalves (Serra Alta Formation), Parana Basin. Anais da Academia Brasileira de Ciências, 69(2): 279279.

GHILARDI, R.P. \& SIMÕES, M.G. (2002) Foram os bivalves do Grupo Passa Dois (exclusive Formação Rio do Rasto), Neopermiano, invertebrados tipicamente dulcícolas? Pesquisas em Geociências, 29: 3-13.

HACHIRO, J., COIMBRA, A.M. \& MATOS, S.L.F. (1993) O caráter cronoestratigráfico da Unidade Irati. In. SIMPÓSIO SOBRE CRONOESTRATIGRAFIA DA BACIA DO PARANÁ, Rio Claro, Resumos, IGCE-UNESP, pp. 62-63.

HAYAMI, I. (1997) Size changes of bivalves and a hypothesis about the cause of mass extinction. Fossils, 62: 24-36.

HAYAMI, I. (1998) Ecology of mass extinctions: the diversity and shell size of bivalves through time. Fossils, 52: 38-44.

HOLDHAUS, K. (1918) Sobre alguns lamelibrânquios fósseis do sul do Brasil. Serviço Geológico e Mineralógico, 2: 1-24.

HOLZ, M., FRANÇA, A.B., SOUZA, P.A., IANNUZZI \& R., ROHN, R., (2010) A stratigraphic chart of the Late Carboniferous/Permian succession of the eastern border of the Paraná Basin, Brazil, South America. Journal of South American Earth Sciences, 29: $381-399$.

KAZUBEK, M.F., \& SIMÕES, M.G. (2002) The lost fauna unearthed: Permian bivalves of the Irati Formation (Passa Dois Group), Paraná Basin, Brazil. In: Paleo - 2002, Porto Alegre, Paleontologia em Destaque 40: 31

KAZUBEK, M.F. \& SIMÕES, M.G. (2003a) Permian bivalves of the Irati Formation (Passa Dois Group, Paraná Basin) and their paleoecological significance. In: XVIII Congresso Brasileiro de Paleontologia, Brasília, Boletim de Resumos, 1: 161. 
KAZUBEK, M.F. \& SIMÕES, M.G. (2003b) Feições sedimentológicas, bioestratinômicas e estratigráficas das concentrações de bivalves do Membro Taquaral (Formação Irati, Grupo Passa Dois, Bacia do Paraná) e seus significados. In: Paleo-2003, Curitiba, Paleontologia em Destaque, 44: 29.

KAUFFMAN, E.G. (1984) Paleobiogeography and evolutionary response dynamic in the Cretaceous Western Interior Seaway of North America. In: WESTERMANN, G.E.G. (Ed.), Jurassic-Cretaceous biochronology and paleogeography of North America. Special Paper. Geological Association of Canada, St. John, 27, 273-306.

KOWALEWSKI, M.; SIMÕES, M.G.; TORELLO, F.F.; MELLO, L.H.C \& GHILARDI, R.P. (2000) Drill holes in shells of Permian benthic invertebrates. Journal of Paleontology, 74: 532-543.

LAGES, L.C. (2004) A Formação Irati (Grupo Passa Dois, Permiano, Bacia do Paraná) no furo de sondagem FP-01-PR (Sapopema, PR). Dissertação de mestrado. Instituto de Geociências e Ciências Exatas. Universidade Estadual Paulista, UNESP, 117 pp.

LINNAEUS, C. (1758) Systema naturae per regna tria naturae, secundum classes, ordines, genera, species, cum characteribus, differentiis, synonymis, locis. Tomus I. Holmiae. (Laurentii Salvii), p.645

MARANHÃO, M.S.A.S. (1986) Contribuição ao conhecimento da malacofauna das camadas basais da Formação Corumbataí (Permiano), Estado de São Paulo. Dissertação de Mestrado. Instituto de Geociências, Universidade de São Paulo, USP, $88 \mathrm{p}$.

MARANHÃO, M.S.A.S. (1995) Fósseis das Formações Corumbataí e Estrada Nova do Estado de São Paulo: subsídios ao conhecimento paleontológico e bioestratigráfico. Tese de Doutorado. Instituto de Geociências, Universidade de São Paulo, USP, 2 v. $250 \mathrm{p}$

MENDES, J.C. (1949) Novos lamelibrânquios fósseis da Série Passa Dois (Sul do Brasil). Rio de Janeiro, DNPM/DGM. Boletim, 133, 40p.

MENDES, J.C. (1952) A Formação Corumbataí na região do Rio Corumbataí. (Estratigrafia e descrição dos lamelibrânquios). Boletim da FCLF-USP, 145, Geologia, 8: 1-119.

MEZZALIRA, S., MENDES, J. C. \& MARANHÃO, M.S.A.S. (1990) Anhembia: novo gênero de bivalves do Grupo Passa Dois - Permiano. Revista do Instituto Geológico, 811: $51-54$.

NEVES, J.P.; ROHN, R. \& SIMÕES, M.G. (2010) Tafonomia de Biválvios em Calcários 
Oolíticos da Formação Teresina (Bacia do Paraná, Permiano Médio, Prudentópolis, PR). Revista do Instituto de Geociências - USP, Sér. cient., São Paulo, 10: 19-36.

NEVES, J.P.; ROHN, R. \& SIMOES, M.G. (2011) Tafonomia de tempestitos conchíferos amalgamados da Formação Teresina em Rio Preto (Estado do Paraná, Permiano Médio, Bacia do Paraná) e suas implicações paleoambientais. Revista do Instituto de Geociências - USP, Série científica, 11: 131-147.

NEVES, J.P.; ANELLI, L.E. \& SIMÕES, M.G. (2014) Early Permian post-glacial bivalve faunas of the Itararé Group, Paraná Basin, Brazil: paleoecology and biocorrelations with South American intraplate basins. Journal of South American Earth Sciences, 52: 203233.

OSCHMANN, W. (1994) Adaptive pathways of marine benthic organisms in oxygencontrolled environments. Neues Jahrbuch für Geologie und Paläontologie, 191: 393444 .

ROCHA-CAMPOS, A.C. (1970a) Moluscos permianos da Formação Rio Bonito. Boletim do Departamento Nacional de Produção Mineral, 89p.

ROCHA-CAMPOS, A.C. (1970b) Glacial-features and paleogeography of the Upper Paleozoic Itararé Subgroup (Tubarão Group) and Aquidauana Group in the Paraná Basin of Southeastern Brazil. In: CONGRESSO LATINOAMERICANO DE GEOLOGIA, Resumenes 1. pp. 194-195.

ROHN, R. (1994) Evolução ambiental da Bacia do Paraná durante o Neopermiano no leste de Santa Catarina e do Paraná. Tese de Doutoramento, Instituto de Geociências, Universidade de São Paulo, USP, 480p.

ROHN, R., LAGES, L.C. \& PENATTI, J.R.R. (2003) Litofácies da Formação Irati no furo de sondagem FP-01-PR (Permiano, borda leste da Bacia do Paraná). In: II Congresso Brasileiro de P\&D em Petróleo \& Gás, Rio de Janeiro, Resumos, 1: 1-6.

RUNNEGAR, B. \& NEWELL, N.D. (1971) Caspian- like relict moluscan fauna in the South America Permian. Bulletin of the American Museum of Natural History, 146: 1-66.

SAGEMAN, B.B., WIGNALL, P.B. \& KAUFFMAN, E.G. (1991) Biofacies models for organic-rich facies: tool for paleoenvironmental analysis. In: EINSELE, G., SEILACHER, A., RICKEN, W. (Eds.), Cycles and Events in Stratigraphy. Springer Verlag, Berlin, pp.542-564. 
SALVADOR, R. B. \& SIMONE, L. R. L. (2009) Técnicas para o processamento de fósseis de bivalves: um estudo de caso sobre a Formação Corumbataí, Bacia do Paraná, Brasil. Revista da Biologia, 3: 24-28.

SALVADOR, R. B. \& SIMONE, L. R. L. (2010) Histórico dos estudos sobre a malacofauna fóssil da Formação Corumbataí, Bacia do Paraná, Brasil. Revista da Biologia, 5: 19-23.

SCHNEIDER, R.L., MÜHLMANN, H., TOMMASI, E., MEDEIROS, R.A., DAEMON, R.F. \& NOGUEIRA, A.A. (1974) Revisão estratigráfica da Bacia do Paraná. In: Anais do XXVIII Congresso Brasileiro de Geologia, 1, pp. 41-65.

SIMÕES, M.G. (1992) Pelecípodes da Formação Palermo (Permiano) de São Sepé (RS) e Guiratinga (MT): implicações na evolução da fauna Neopaleozóica da Bacia do Paraná, Brasil. Tese de doutorado. Instituto de Geociências, Universidade de São Paulo, USP. 286pp.

SIMÕES, M.G. (2000) Assembleias de invertebrados marinhos do Neopaleozóico da Bacia do Paraná, no Estado do Rio Grande do Sul, Brasil. In: HOLZ, M.; DE HOS, L.F. (Orgs.). Paleontologia do Rio Grande do Sul. 1 ed. Porto Alegre, RS: CIGO/UFRGS, 1, pp.107-125.

SIMÕES, M.G. \& ANELLI, L.E. (1995) Runnegariella, um novo gênero de Megadesmidae (Pelecypoda) da Formação Corumbataí (Neopermiano), Bacia do Paraná, Brasil. Revista Geociências, 14: 161-173.

SIMÕES, M.G. \& ANELLI, L.E. (2010) Taxonomic position of Guiratingia mendesi (Megadesmidae) and the evolution of permian endemic bivalve fauna of the Paraná Basin, Brazil. Revista Brasileira de Paleontologia, 13: 167-174.

SIMÕES, M.G. \& FITTIPALDI, F.C. (1987) Bivalves do Grupo Passa Dois, Permiano da Bacia do Paraná: sinopse das pesquisas. In: VI SIMPÓSIO REGIONAL DE GEOLOGIA, Rio Claro, Atas, 1: 281-295.

SIMÕES, M.G. \& FITTIPALDI, F.C. (1992) Fósseis da região de Rio Claro. Arquivo do Município de Rio Claro, 77p.

SIMÕES, M.G. \& KOWALEWSKI, M. (1998) Shell beds as paleoecological puzzles: a case study from the Upper Permian of the Paraná Basin, Brazil. Facies, 38: 175-196.

SIMOES, M.G. \& MELLO, L.H.C. (1996) Sistemática e Paleocologia de Casterella gratiosa Mendes (Mollusca, Pelecypoda), Formações Terezina e Corumbataí (Permiano Superior), Bacia do Paraná, Brasil. Acta Geológica Leopoldensia, 43: 5-23.

SIMÕES, M.G. \& TORELLO, F.F. (2003) Modelo de tafofácies para os moluscos bivalves 
do Grupo Passa Dois (Formações Serra Alta, Teresina e Corumbataí), Permiano Superior, Bacia do Paraná, Brasil. Revista Brasileira de Geociências, 33: 1-10.

SIMÕES, M.G.; TORELLO, F.F. \& ROCHA-CAMPOS, A.C. (1996) Gênese e Classificação da Coquina de Camaquã, Formação de Corumbataí (Neopermiano), na Região de Rio Claro, SP. Anais da Academia Brasileira de Ciências, 68: 545-557.

SIMÕES, M.G.; MARQUES, A.C.; MELLO, L.H.C. \& ANELLI, L.E. (1997) Phylogenetic analysis of the genera of the extinct Family Megadesmidae (Pelecypoda, Anomalodesmata), with remarks on its paleoecology and taxonomy. Journal of Comparative Biology, 2: 75-90.

SIMÕES, M.G.; ROCHA-CAMPOS, A.C. \& ANELLI, L.E. (1998) Paleoecology and evolution of Permian pelecypod assemblages (Paraná Basin) from Brazil. In: JOHNSTON, P.A. \& HAGGART, J.W. (Ed.) Bivalves - An Eon of evolution: paleobiological studies honoring Norman D. Newell. Calgary: University of Calgary Press, p. 443-452.

SIMÕES, M.G.; MELLO, L.H.; TORELLO, F.F. \& GHILARDI, R.P. (2000a) Tambaquyra gen.n. (Bivalvia, Anomalodesmata), Formação Serra Alta (Neopermiano), Grupo Passa Dois, Bacia do Paraná, Brasil. Revista Universidade de Guarulhos, Série Geociências, 6: $11-19$.

SIMÕES, M.G.; KOWALEWSKI, M.; TORELLO, F.F.; GHILARDI, R.P. \& MELLO, L.H.C. (2000b) Early onset of Modern-Style shell beds in the Permian sequences of the Paraná basin: implications for the Phanerozoic trend in bioclastic accumulations. Revista Brasileira de Geociências, 30: 499-503.

SIMÕES, M.G.; TORELLO, F.F.; MELLO, L.H.C \& GHILARDI, R.P. (2000c) O conteúdo fossilífero de novos afloramentos do Grupo Passa Dois (Neopermiano), nas porções centro sul e nordeste do Estado de São Paulo: implicações bioestratigráficas e paleoecologicas. Acta Geologica Leopoldensia, 23: 61-90.

SIMÕES, M.G., MATOS, S. A., ANELLI, L.E., ROHN, R., WARREN, L.V. \& DAVID, J.M. (2015) A new Permian bivalve-dominated assemblage in the Rio do Rasto Formation, Paraná Basin, Brazil: Faunal turnover driven by regional-scale environmental changes in a vast epeiric sea. Journal of South American Earth Sciences, 64: 14-26.

TABOADA, A.C.; NEVES, J.P.; WEINSCHÜTZ, L.C.; PAGANI, M.A. \& SIMÕES, M.G. (2016) Eurydesma-Lyonia fauna (Early Permian) from the Itararé Group, Paraná Basin 
(Brasil): A Paleobiogeographic W-E Trans-Gondwanan marine connection. Palaeogeography, Palaeoclimatology, Palaeoecology, 449: 431-454.

TEIXEIRA, C.A.S. (2014) Evolução térmica e paleofluídos dos folhelhos da Formação Serra Alta na borda leste da Bacia do Paraná. Dissertação de Mestrado. Instituto de Geociências, Universidade de São Paulo, USP. 100pp.

TWITCHETT, R.J. (2007) The Lilliput effect in the aftermath of the end-Permian extinction event. Palaeogeography, Palaeoclimatology, Palaeoecology, 252, 132-144.

WARREN, L.V.; ASSINE, M.L.; SIMÕES, M.G.; RICCOMINI, C. \& ANELLI, L.E. (2015) A Formação Serra Alta, Permiano, no Centro-Leste do Estado de São Paulo, Bacia do Paraná, Brasil. Brazilian Journal of Geology, 45: 127-142.

WESSELING, F.P. (2007) Long-lived lake molluscs as island faunas: a bivalve perspective, In: RENEMA, W. (Ed.). Biogeography, time and place: distributions, barriers and islands, Dordrecht: Springer, p. 275-314. 
PARTE 2

2. MATERIAIS \& MÉTODOS 
$\mathrm{Na}$ presente tese todos os resultados são apresentados na forma de artigos científicos (em anexo). Assim sendo, as informações referentes aos aspectos geológicos das áreas de estudo e os métodos empregados estão detalhadamente descritos nos respectivos artigos. Nessa seção serão apresentados, de maneira resumida, apenas os aspectos mais gerais da metodologia utilizada. O leitor interessado deverá consultar os artigos para os detalhes metodológicos empregados.

\subsection{GEOLOGIA DA ÁREA DE ESTUDO}

O Grupo Passa Dois (Bacia do Paraná, Brasil), é constituído por depósitos permianos, inseridos na supersequência Gondwana I (Milani, 1997; Milani et al., 1998, 2007a). A sucessão sedimentar tem início com os depósitos de folhelhos negros, ricos em matéria orgânica e calcários da Formação Irati, os quais registram condições de anoxia e restrição paleogeográfica da bacia (Araújo, 2001; Araújo et al., 2001; Milani et al., 2007a; Holz et al., 2010). Essa unidade é sucedida pela Formação Serra Alta, representada principalmente por argilitos que registra o último evento transgressivo da bacia. A unidade é seguida pelas formações Teresina e Corumbataí, que representam uma longa fase regressiva, culminando com a deposição de sedimentos fluviais, deltaicos e eólicos da Formação Rio do Rasto (Zalán et al., 1991; Sousa et al., 1991; Rohn, 1994; Simões et al., 1998, 2015; Wesselingh, 2007; Warren et al., 2008, 2015; Holz et al., 2010).

A Formação Irati (Artinskiano-Kunguriano; Almeida \& Barbosa, 1953) possui aproximadamente 60 metros de espessura e está intercalada entre as formações Palermo (Grupo Guatá) e Serra Alta (Grupo Passa Dois). Sua porção basal (Membro taquaral) é caracterizada por folhelhos pirobetuminosos, ricos em matéria orgânica e argilitos. A parte superior da unidade (= Membro Assistência) é constituída por argilitos e siltitos intercalados a camadas tabulares de calcário (Schneider et al., 1974; Araújo et al., 2001; Hachiro et al., 1993; Hachiro, 1996). Os altos teores de TOC (matéria orgânica total), maiores que 17\%, (Milani et al., 2007b), assim como a quase completa ausência de invertebrados bentônicos e traços fósseis, sugerem que os folhelhos e muito dos pacotes de calcários devem ter sido depositados sob condições de anoxia (Amaral, 1971; Subacius \& Amaral, 1983; Maynard et al., 1996; Hachiro, 1996; Faure \& Cole, 1999; Calça \& Fairchild, 2012).

A Formação Serra Alta (Kunguriano) possui cerca de 50-70 metros de espessura e é representada por uma sucessão onde predominam siltitos de coloração cinza escura e folhelhos negros. Também podem ser encontradas camadas delgadas (decimétricas) de 
arenitos finos e raras camadas de calcário (Sanford \& Lange 1960; Schneider et al., 1974; IPT, 1981; CPRM, 2006; Meglhioratti, 2006; Holz et al., 2010; Warren et al., 2015). Esta unidade se encontra depositada sobre a Formação Irati e é sucedida pela Formação Teresina. De acordo com a literatura (Schneider et al., 1974; Araújo, 2001; Meglhioratti, 2006), a Formação Serra Alta tem sido interpretada como depositada em ambiente marinho, abaixo do nível de base de ondas de tempestade, sob condições de deficiência nas concentrações de oxigênio.

Os afloramentos aqui estudados na Formação Irati, em pedreiras abandonadas/ativas no município de Irati, Estado do Paraná (Anexo 1; Fig. 4), são constituídos, predominantemente, de folhelhos negros e folhelhos sílticos de coloração cinza escura, pertencentes ao Membro Taquaral (membro inferior da Formação Irati) (Anexo 1; Fig. 5). Neste contexto, duas das seis pedreiras encontradas na região puderam ser detalhadamente estudadas (Seções A e B) (Anexo 1; Figs. 5, 6 e 7). As seções possuem cerca de 15 metros de extensão e estão localizadas logo acima do contato com a Formação Palermo (Artinskiano médio; Holz et al., 2010). Ao longo da seção podem ser encontrados dispersos nos folhelhos, fragmentos de insetos, plantas, crustáceos do gênero Clarkecaris, escamas e dentes de peixes.

Na sucessão estudada (Anexo 1; Fig. 5), foi possível identificar três ciclos métricos caracterizados por folhelhos negros na porção basal e folhelhos sílticos na porção superior (granocrescência ascendente). O topo do ciclo mais basal (Ciclo 1) é marcado pela ocorrência de inúmeros pavimentos de conchas desarticuladas de bivalves (Anexo 1; Fig. 8), aqui descritos pela primeira vez. Os pavimentos estudados possuem espessura milimétrica e se encontram alternados a camadas milimétricas de folhelhos, constituindo um pacote de aparência rítmica que pode ser mapeado por mais de 10 quilômetros (Anexo 1; Fig. 6).

A sucessão estudada da Formação Serra Alta, aflora no centro-oeste do Estado de São Paulo, às margens da Rodovia Castello Branco (SP-280), aproximadamente a oito quilômetros da cidade de Porangaba (Anexo 2; Fig. 1). O principal afloramento estudado (km 160,7) foi selecionado para estudo com base em interpretações anteriores que demonstraram que a sucessão sedimentar, predominantemente pelíticas e de coloração escura, teria sido depositada em condições de costa à fora (offshore), e com variação nas taxas de oxigenação de fundo (Sousa, 1985; Simões et al., 2000a, b; Warren et al., 2015; Bondioli et al., 2015). De modo complementar, foram analisados outros três afloramentos, também às margens ou próximos da Rodovia Castello Branco (SP-280), ou seja: (a) Afloramento localizado em frente ao principal afloramento estudado, no canteiro central da rodovia (km 160,7) (Anexo 3; 
Fig. 1D). Nesta exposição, a camada de calcário brechado (discutida nos artigos em anexo), está também presente, possibilitando a observação de estruturas sedimentares em planta. Nesta visão é possível observar a presença de estruturas elevadas associadas à camada de calcário. (b) Afloramento situado cerca de 450 metros após o pedágio de Porangaba-SP, em direção à capital, nas margens da rodovia. Neste afloramento, siltitos da base da Formação Serra alta estão expostos (Anexo 3; Fig. 1C). (c) Afloramento localizado às margens do córrego Alelúia, situado cerca de 100 metros do retorno do pedágio de Porangaba-SP (Anexo 3; Fig. 1C). A sucessão exposta contém o contato entre as formações Irati (subjacente) e Serra Alta (sobrejacente).

O afloramento principal é constituído, predominantemente, por uma sucessão aparentemente monótona de 11 metros onde predominam siltitos (Anexo 2; Fig 2). Um olhar atento permite observar que os siltitos estão intercalados a raras camadas centimétricas/decimétricas de arenitos e calcários, assim como níveis bem marcados de concreções carbonáticas e nódulos fosfáticos (Anexo 2; Figs.3, 4, 5 e 6). Fósseis de moluscos bivalves são encontrados preferencialmente como moldes preservados nos siltitos maciços ou dentro das concreções carbonáticas, apresentando as conchas preservadas. Planolites e Thalassinoides podem ser encontrados em níveis específicos da sucessão.

\subsection{Procedimentos metodológicos}

Os afloramentos estudados foram georreferênciados e descritos, assim como elaborados os perfis colunares. Particular atenção foi dada a descrição dos litótipos, sua distribuição vertical e lateral, geometria, estruturas sedimentares e contatos das diferentes camadas, e em especial, das camadas que continham os fósseis estudados. Os bivalves foram coletados em campo, considerando sua orientação e posição estratigráfica, sempre que possível. Concreções e outras estruturas, como os mounds (vide anexo 3) foram contados e medidas do eixo maior (= comprimento) e diâmetro foram, respectivamente, realizadas em campo. Sempre que necessário, blocos de rochas (= slabs) e concreções carbonáticas foram seccionados e polidos no laboratório, permitindo a observação e descrição detalhada das estruturas sedimentares, biofábrica, taxas de bioturbações, dentre outras feições.

Com relação às análises tafonômicas, a biofábrica (sensu Fürsich \& Oschmann, 1993), seleção de tamanho e de valvas, orientação (em planta e em seção), articulação e fragmentação foram medidos quantitativamente (e.g., Kidwell et al., 1986; Kidwell, 1991; Kidwell \& Holland, 1991; Fürsich \& Oschmann, 1993). Os termos descritivos e parâmetros 
utilizados foram fundamentados em Kidwell et al. (1986), Brett \& Baird (1986), Fürsich \& Oschmann (1986, 1993), Kidwell \& Holland (1991) e Simões \& Kowalewski (1998). Para os pavimentos, a abundância das conchas (grau de cobertura, sensu Posenato et al., 2013, p. 266) foi quantitativamente estabelecida. Diagramas de roseta foram elaborados para os pavimentos de conchas provenientes da Formação Irati, neles foram plotadas as frequências de direção do eixo maior das conchas. Dessa forma, os diagramas indicam a direção perpendicular a paleocorrente. Considerando que vários pavimentos não possuem dados para orientação em planta, os diagramas de roseta foram rotacionados para que as maiores frequências se ajustassem a direção N-S (Anexo 1).

Os espécimes foram identificados com base em Mendes (1949; 1952), Runnegar \& Newell (1971), Mezzalira et al. (1990), Simões \& Anelli (1995), Simões et al. (1997) e Simões et al. (2000a). A classificação supragenérica empregada foi a de Bieler et al. (2010) e Carter et al. (2011). A paleoautoecologia dos bivalves estudados foi inferida com base em Simões et al. (1998), Ghilardi (1999) e Wesselingh (2007). Finalmente, o arcabouço bioestratigráfico utilizado foi o de Rohn (1994).

A análise dos traços fósseis foi realizada com base no Índice de bioturbação (BI), de acordo com Taylor \& Goldring (1993), segundo o qual: BI 0 (sem bioturbação); BI 1(bioturbação esparsa, poucos traços discretos e/ou estruturas de fuga); BI 2 (bioturbação baixa, densidade de traços baixa, estruturas de fuga sempre comuns); BI 3 (bioturbação moderada, traços discretos, sobreposições raras); BI 4 (bioturbação elevada, alta densidade de traços, sobreposições comuns); BI 5 (bioturbação intensa, estruturas sedimentares completamente destruídas, retrabalhamento limitado, furos tardios discretos), e BI 6 (bioturbação completa, retrabalhamento do sedimento devido a repetidas sobreposições).

Foi adotado para as interpretações paleoecológicas o modelo tripartite de oxigenação relativa das águas de fundo, segundo Rhoads \& Morse (1971); Byers (1977); Savrda et al. (1984); Thompson et al. (1985), Savrda \& Bottjer (1987,1991), Tyson \& Pearson (1991), Sageman et al. (1991), Oschmann (1991a,b) e Sageman \& Bina, (1997). Neste modelo são consideradas três principais biofácies: a) aeróbia: caracterizada por alta diversidade e abundância biológica, incluindo espécies que possuem esqueletos calcáreos. O substrato é bioturbado devido à intensa atividade da fauna $\left(>2 \mathrm{ml} \mathrm{O}_{2} / 1 \mathrm{H}_{2} \mathrm{O}\right)$; b) disaeróbia: ambiente restrito, com baixa diversidade e predomínio de organismos de corpo mole. Raridade ou ausência de organismos muito calcificados. Substrato bioturbado pela fauna resistente. $\left(2-0.2 \mathrm{ml} \mathrm{O}_{2} / \mathrm{L}\right)$; c) anaeróbia: ausência de metazoários e bioturbação. Substratos 
laminados $\left(0-0.2 \mathrm{ml} \mathrm{O}_{2} / \mathrm{L}\right)$. Segundo Savrda \& Bottjer (1987), podemos reconhecer também a condição exaeróbia, localizada no limite entre as condições disaeróbia e anaeróbia $(0.1$ $0.2 \mathrm{ml} / \mathrm{L}$ ) e caracterizada por substratos com ausência de bioturbação, contendo ocorrências anômalas de organismos relativamente grandes, com esqueleto calcário (Savrda \& Bottjer, 1987). Nessas condições, o balanço entre a disponibilidade de $\mathrm{O}_{2}$ e $\mathrm{H}_{2} \mathrm{~S}$ é ideal para o estabelecimento de relacionamentos quimiossimbiontes entre a fauna bentônica e bactérias quimiossintetizantes (Savrda \& Bottjer, 1987).

Finalmente, análises de $\delta^{13} \mathrm{C}$ e $\delta^{18} \mathrm{O}$ para o calcários brechado e conchas de bivalves foram realizadas pelo Beta Analytic, USA, combinado com os dados disponíveis em Alessandretti et al. (em preparação).

Os espécimes, concreções, e blocos de rochas coletados e utilizados neste estudo estão depositados sob o código DZP na coleção científica do Laboratório de Paleozoologia Evolutiva, Departamento de Zoologia, Instituto de Biociências da Unesp, Campus de Botucatu.

\subsection{REFERÊNCIAS BIBLIOGRÁFICAS}

ALESSANDRETTI, L. et al. (em preparação) A singular Permian methane seep system in the Paraná Basin revealed by clastic dykes and fossil-rich carbonate concretions.

ALMEIDA, F.F.M. \& BARBOSA, O. (1953) Geologia das quadrículas de Piracicaba e Rio Claro, Estado de São Paulo. Boletim da Divisão de Geololgia e Mineralogia, 143.

AMARAL, S.E. (1971) Geologia e petrologia da Formação Irati (Permiano) no Estado de São Paulo. Boletim do IGA, 2: 3-81.

ARAÚJO, L.M. (2001) Análise da expressão estratigráfica dos parâmetros de geoquímica orgânica nas Seqüências Deposicionais Irati. Tese de Doutorado. Universidade Federal do Rio Grande do Sul, 307pp.

ARAÚJO, L.M., RODRIGUES, R. \& SCHERER, C.M.S. (2001) Sequências deposicionais Irati: arcabouço químio-estratigráfico e inferências paleoambientais. Ciência-TécnicaPetróleo, 20: 193-202.

BIELER, R., CARTER, J.G. \& COAN, E.V. (2010) Classification of bivalve families. Malacologia, 52: 113-133.

BRETT, C.E. \& BAIRD, G.C. (1986) Comparative taphonomy: a key to paleoevironmental interpretation based on fossil preservation. Palaios, 1: 207-227. 
BYERS, C. W. (1977) Biofacies pattern in euxinic basins: a general model. In: COOK, H. E. \& ENOS, P. (Eds.) Deep-water carbonate Environments. Society of Economic Paleontologists and Mineralogists Special Publication, 25: 5-17.

BONDIOLI, J.G., MATOS, S.A., WARREN, L.V., ASSINE, M.L., RICCOMINI, C. \& SIMÕES M.G. (2015) The interplay between event and background sedimentation and the origin of fossil-rich carbonate concretions: a case study in Permian rocks of the Paraná Basin, Brazil. Lethaia, 48: 522-539.

CALÇA, C.P. \& FAIRCHILD, T.R. (2012) Petrographic approach to the study of organic microfossils from the Irati Subgroup (Permian, Paraná Basin, Brazil). Journal of South American Earth Sciences, 35: 51-61.

CARTER, J.G.; ALTABA, C.R.; ANDERSON, L.C.; ARAUJO, R.; BIAKOV, A.S.; BOGAN, A.E.; CAMPBELL, D.C.; CAMPBELL, M.; JIN-HUA, C.; COPE, J.C.W.; DELVENE, G.; DIJKSTRA, H.H.; ZONG-JIE, F.; GARDNER, R.N.; GAVRILOVA, V.A.; GONCHAROVA, I.A.; HARRIES, P.J.; HARTMAN, J.H.; HAUTMANN, M.; HOEH, W.R.; HYLLEBERG, J.; BAO-YU, J.; JOHNSTON, P.; KIRKENDALE, L.; KLEEMAN, K.; HOPPKA, J.; KRIZ, J.; MACHADO, D.; MALCHUS, N.; MÁRQUEZ-ALIAGA, A.; MASSE, J.P.; MCROBERTS, C.A.; MIDDELFART, P.U.; MITCHELL, S.; NEVESSKAJA, L.A.; ÖZER, S.; POJETA, J.J.; POLUBOTKO, I.V.; PONS, J.M.; POPOV, S.; SÁNCHEZ, T.; SARTORI, A.F.; SCOTT, R.W.; SEY, I.I.; SIGNORELLI, J.H.; SILANTIEV, V.V.; SKELTON, P.W.; THOMAS, S.; WATERHOUSE, J.B.; WINGARD, G.L. \& YANCEY, T. (2011) A Synoptical classification of the bivalvia (Mollusca). Paleontological contributions, 4: 1-47.

CPRM - Serviço Geológico do Brasil., 2006. Mapa Geológico do Estado de São Paulo.- SIG Brasil, scale 1:750.000.

FAURE, K. \& COLE, D. (1999) Geochemical evidence for lacustrine microbial blooms in the vast Permian Main Karoo, Parana, Falkland Islands and Huab basins of southwestern Gondwana. Palaeogeography, palaeoclimatology, palaeoecology, 152(3-4): 189-213.

FÜRSICH, F.T. \& OSCHMANN, W. (1986) Storm shell beds of Nanogyra virgula in the Upper Jurassic of France. Neues Jahrbuch für Geologie und Paläontologie. 172: 141161.

FÜRSICH, F.T. \& OSCHMANN, W. (1993) Shell beds as tool in basin analysis: the Jurassic of Kachchh, western India. Journal of the Geological Society, London, 150: 169-185. 
GHILARDI, R.P. (1999) Paleoautoecologia dos bivalves do Grupo Passa Dois (Neopermiano) no Estado de São Paulo: bivalves fósseis como indicadores da dinâmica sedimentar. Dissertação de Mestrado. Instituto de Geociências, USP, 160pp.

HACHIRO, J. (1996) O Subgrupo Irati (Neopermiano) da Bacia doParaná. Tese de Doutoramento. Instituto de Geociências, USP, 196 p.

HACHIRO, J., COIMBRA, A.M. \& MATOS, S.L.F. (1993) O caráter cronoestratigráfico da Unidade Irati. In: SIMPÓSIO SOBRE CRONOESTRATIGRAFIA DA BACIA DO PARANÁ, Rio Claro, Resumos, IGCE-UNESP, pp. 62-63.

HOLZ, M., FRANÇA, A.B., SOUZA, P.A., IANNUZZI \& R., ROHN, R. (2010) A stratigraphic chart of the Late Carboniferous/Permian succession of the eastern border of the Paraná Basin, Brazil, South America. Journal of South American Earth Sciences, 29: $381-399$.

IPT - Instituto de Pesquisas Tecnológicas., 1981. Carta Geológica do Estado de São Paulo, scale 1: 500.000 .

KIDWELL, S.M. (1991) The stratigraphy of shell concentrations. In: ALLISON, P.A. \& BRIGGS, D.E.G. (Eds.), Taphonomy, Releasing the Data Locked in the Fossil Record. Topics in Geobiology. Plenum Press, New York. 9: 211-290.

KIDWELL, S.M. \& HOLLAND, S.M. (1991) Field description of coarse bioclastics fabrics. Palaios, 6: 426-434.

KIDWELL, S.M., FÜRSICH, F.T. \& AIGNER T. (1986) Conceptual framework for the analysis of fossil concentrations. Palaios, 1: 228-238.

MAYNARD, J.B., CHOCYK, J.M., GAINES, R.R., KREKELER, M.P., PROKOPENKO, M., SUMMERS, A.M. \& HUFF, W.D. (1996) Bentonites in the Late Permian (Tatarian) Irati Formation of Brazil: geochemistry and potential of stratigraphic correlation. In: XXVIII Geological Society of America Annual Meeting, Denver. Abstracts, pp. 280.

MEGLHIORATTI, T. (2006) Estratigrafia de sequencias das formações Serra Alta, Teresina e Rio do Rasto (Permiano da Bacia do Paraná) na porção nordeste do Paraná e centrosul de São Paulo. Tese de Mestrado. Instituto de Geociências e Ciências Exatas, Universidade Estadual Paulista.

MENDES, J.C. (1949) Novos lamelibrânquios fósseis da Série Passa Dois (Sul do Brasil). Rio de Janeiro, DNPM/DGM. Boletim, 133, 40p.

MENDES, J.C. (1952) A Formação Corumbataí na região do Rio Corumbataí. (Estratigrafia e 
descrição dos lamelibrânquios). Boletim da FCLF-USP, 145, Geologia, 8: 1-119.

MEZZALIRA, S., MENDES, J. C. \& MARANHÃO, M.S.A.S. (1990) Anhembia: novo gênero de bivalves do Grupo Passa Dois - Permiano. Revista do Instituto Geológico, 811: $51-54$.

MILANI, E.J. (1997) Evolução Tectono-Estratigráfica da Bacia do Paraná e seu relacionamento com a Geodinâmica Fanerozóica do Gondwana Sul-Ocidental. Tese de Doutorado, Universidade Federal do Rio Grande do Sul, 254pp.

MILANI, E.J., FACCINI, U.F., SCHERER, C.M.S., ARAÚJO, L.M. \& CUPERTINO, J.A. (1998) Sequences and stratigraphic hierarchy of the Paraná Basin (Ordovician to Cretaceous), Southern Brazil. Boletim IG-USP, Série científica, 29: 125-173.

MILANI, E.J., MELO, J.H.G., SOUZA, P.A., FERNANDES, L.A. \& FRANÇA, A.B. (2007a). Bacia do Paraná. Boletim de Geociências da Petrobras, 15: 265-287.

MILANI, E. J., FRANÇA, A.B. \& MEDEIROS, R.A. (2007b) Rochas geradoras e rochas reservatório da Bacia do Paraná, faixa oriental de afloramentos, Estado do Paraná. Boletim de Geociências da Petrobras, 15: 135-162.

OSCHMANN,W. (1991a) Anaerobic-poikiloaerobic-aerobic: a new zonation for modern and ancient neritic redox facies. In: EINSELE,G., RICKEN,W. \& SEILACHER,A. (Eds.) Events and cycles in stratigraphy. Springer-Verlag, Heidelberg. p. 565-571.

OSHMANN, W. (1991b) Distribution, dynamics and palaeoecology of Kimmeridgian Upper Jurassic) shelf anoxia in western Europe. In: TYSON, R. V. \& PEARSON, T. H. (Eds) Modern and Ancient Continental Shelf Anoxia. 58: 381-395.

POSENATO, R., BASSI, D. \& AVANZINI, M. (2013) Bivalve pavements from shallowwater black-shales in the Early Jurassic of northern Italy: a record of salinity- and oxygen-depleted environmental evolutionary dynamics. Palaeogeography, Palaeoclimatology, Palaeoecology 369: 262-271.

RHOADS, D.C. \& MORSE, J.W. (1971) Evolutionary and ecologic significance of oxygendeficient marine basins. Lethaia, 4: 413-428.

SOUSA, S.H.M., SUGUIO, K. \& CASTRO J.C. (1991) Sedimentary facies of the Estrada Nova and Corumbataí Formations (Late Paleozoic of the Paraná Basin) in the State of São Paulo, Brazil. In: ULBRICH, H. \& ROCHA CAMPO, A.C. (Eds.) VII International Gondwana Symposium, São Paulo. Proceedings, pp. 161-172.

SUBACIUS, S.M. \& AMARAL, S.E. (1983) Estudo biogeoquímico da matéria orgânica preservada em folhelhos pirobetuminosos próximos a soleiras de diabásio: Formação 
Irati, $\mathrm{SP}=$ Etude biochimique de la matière organique préservée dans des feuillets bitumineux proches de la partie supérieure des diabases: Formation Irati, São Paulo. Anais da Academia Brasileira de Ciências, 55(1): 45-53.

ROHN, R. (1994) Evolução ambiental da Bacia do Paraná durante o Neopermiano no leste de Santa Catarina e do Paraná. Tese de Doutoramento, Instituto de Geociências, Universidade de São Paulo, USP, 480p.

RUNNEGAR, B. \& NEWELL, N.D. (1971) Caspian- like relict moluscan fauna in the South America Permian. Bulletin of the American Museum of Natural History, 146: 1-66.

SAGEMAN, B.B. \& BINA, C.R. (1997) Diversity and Species abundance Patterns in Late Cenomanian Black Shale Biofacies, Western Interior, U.S. Palaios, 12: 449-466.

SAGEMAN, B.B.; WIGNALL, P.B. \& KAUFFMAN, E.G. (1991) Biofacies models for organic-rich facies: tool for paleoenvironmental analysis. In: EINSELE, G., SEILACHER, A., RICKEN, W. (Eds.) Cycles and Events in Stratigraphy. Springer Verlag, Berlin, p. 542-564.

SANFORD, R.M. \& LANGE, F.W. (1960) Basin study approach to oil evaluation of Paraná Miogeosyncline south Brasil. Bulletin of the American Association of Petroleum Geologist, 44: 1316-1374.

SAVRDA, C.E. \& BOTTJER, D.J. (1987) The exaerobic zone, a new oxygen deficient marine biofacies. Nature, 327: 54-56.

SAVRDA, C.E. \& BOTTJER, D.J. (1991) Oxygen-related biofacies in marine strata: an overview and update. Geological Society, London, Special Publications, 58(1): 201219.

SAVRDA, C. E., BO'ITJER, D. J. \& GORSLINE, D. S. (1984) Developments of an oxygendeficient marine biofacies model: Evidence from Santa Monica, San Pedro and Santa Barbara Basins. California continental borderland. Bulletin of the American Association of Petroleum Geologists, 68: 1178-1192.

SCHNEIDER, R.L., MÜHLMANN, H., TOMMASI, E., MEDEIROS, R.A., DAEMON, R.F. \& NOGUEIRA, A.A. (1974) Revisão estratigráfica da Bacia do Paraná. In: Anais do XXVIII Congresso Brasileiro de Geologia, 1, pp. 41-65.

SIMÕES, M.G. \& ANELLI, L.E. (1995) Runnegariella, um novo gênero de Megadesmidae (Pelecypoda) da Formação Corumbataí (Neopermiano), Bacia do Paraná, Brasil. Revista Geociências, 14: 161-173.

SIMÕES, M.G. \& KOWALEWSKI, M. (1998) Shell beds as paleoecological puzzles: a case 
study from the Upper Permian of the Paraná Basin, Brazil. Facies, 38: 175-196.

SIMÕES, M.G.; MARQUES, A.C.; MELLO, L.H.C. \& ANELLI, L.E. (1997) Phylogenetic analysis of the genera of the extinct Family Megadesmidae (Pelecypoda, Anomalodesmata), with remarks on its paleoecology and taxonomy. Journal of Comparative Biology, 2: 75-90.

SIMÕES, M.G.; ROCHA-CAMPOS, A.C. \& ANELLI, L.E. (1998) Paleoecology and evolution of Permian pelecypod assemblages (Paraná Basin) from Brazil. In: JOHNSTON, P.A. \& HAGGART, J.W. (Ed.) Bivalves - An Eon of evolution: paleobiological studies honoring Norman D. Newell. Calgary: University of Calgary Press, p. 443-452.

SIMÕES, M.G.; MELLO, L.H.; TORELLO, F.F. \& GHILARDI, R.P. (2000a) Tambaquyra gen.n. (Bivalvia, Anomalodesmata), Formação Serra Alta (Neopermiano), Grupo Passa Dois, Bacia do Paraná, Brasil. Revista Universidade de Guarulhos, Série Geociências, 6: $11-19$.

SIMÕES, M.G.; TORELLO, F.F.; MELLO, L.H.C \& GHILARDI, R.P. (2000b) O conteúdo fossilífero de novos afloramentos do Grupo Passa Dois (Neopermiano), nas porções centro sul e nordeste do Estado de São Paulo: implicações bioestratigráficas e paleoecologicas. Acta Geologica Leopoldensia, 23: 61-90.

SIMÕES, M.G., MATOS, S. A., ANELLI, L.E., ROHN, R., WARREN, L.V. \& DAVID, J.M. (2015) A new Permian bivalve-dominated assemblage in the Rio do Rasto Formation, Paraná Basin, Brazil: Faunal turnover driven by regional-scale environmental changes in a vast epeiric sea. Journal of South American Earth Sciences, 64: $14-26$.

SOUSA, S.H.M. (1985) Fácies sedimentares das Formações Estrada Nova e Corumbataí no Estado de São Paulo. Tese de Mestrado, Instituto de Geociências, USP.

TAYLOR, A.M. \& GOLDRING, R. (1993) Description and analysis of bioturbation and ichnofabric. Journal of the Geological Society, 150: 141-148.

THOMPSON, J., MUllinS, H. T., NEWTON, C. A. \& VERCOUTERE, T. L. (1985) Alternative biofacies model for dysaerobic communities. Lethaia, 18: 167-179.

TYSON, R.V. \& PEARSON, T.H. (1991) Modern and ancient continental shelf anoxia: an overview. In: TYSON, R.V.\& PEARSON, T.H. Modern and ancient continental shelf anoxia. Geological Society Special Publication, 58: 1-24.

WARREN, L.V., ALMEIDA, R.P., HACHIRO, J., MACHADO, R., ROLDAN, L.F., 
STEINER, S.S., CHAMANI, M.A.C. (2008) Evolução sedimentar da Formação Rio do Rasto (Permo- Triássico da Bacia do Paraná) na porção centro sul do estado de Santa Catarina, Brasil. Revista Brasileira de Geociências, 38: 213-227.

WARREN, L.V.; ASSINE, M.L.; SIMÕES, M.G.; RICCOMINI, C. \& ANELLI, L.E. (2015) A Formação Serra Alta, Permiano, no Centro-Leste do Estado de São Paulo, Bacia do Paraná, Brasil. Brazilian Journal of Geology, 45: 127-142.

WESSELING, F.P. (2007) Long-lived lake molluscs as island faunas: a bivalve perspective, In: RENEMA, W. (ed.). Biogeography, time and place: distributions, barriers and islands, Dordrecht: Springer, p. 275-314.

ZALÁN, P.V, WOLFF, S., VIEIRA, I.S., ASTOLF, M. A., CONCEIÇÃO, J.C.J., ZANOTTO, O. \& APPI, V.T., 1991. Tectonics and sedimentation of the Paraná Basin. In: VII International Gondwana Symposium, São Paulo. Proceedings, pp. 83-117. 
PARTE 3

3. RESULTADOS 


\subsection{ReSUltados ObTidos}

Apresentam-se como resultados obtidos, 4 artigos científicos em preparação, submetidos e/ou publicados (anexos 1, 2, 3 e 4 ), uma vez que, segundo as normas do programa de pós-graduação de Geoquímica e Geotectônica, do IGc-USP, as teses de doutoramento podem ser apresentadas na forma de artigos científicos. Dentro do contexto de internacionalização das universidades estaduais paulistas, os artigos foram redigidos em inglês e elaborados visando publicação internacional, em periódicos de alto impacto na área.

No artigo no anexo 1, "PERMIAN ENDEMIC BIVALVES OF THE "IRATI ANOXIC CRISIS”, PARANÁ BASIN, BRAZIL: TAPHONOMICAL, PALEOGEOGRAPHICAL AND EVOLUTIONARY IMPLICATIONS", foi descrita uma nova assembleia de bivalves permianos para a Formação Irati, Grupo Passa Dois, Bacia do Paraná, Brasil. Esse artigo foi submetido ao periódico Palaeogeography Palaeoclimatology Palaeoecology, e aguarda parecer.

$\mathrm{O}$ artigo no anexo 2, "UNTOLD MUDDY TALES: REVEALING THE PALEOENVIRONMENTAL DYNAMICS OF A "BARREN" MUDROCK SUCCESSION FROM A SHALLOW PERMIAN EPEIRIC SEA”, demonstra, através da análise integrada (sedimentológica, palentológica e tafonômica) que a Formação Serra Alta (Grupo Passa Dois, Bacia do Paraná, Brasil), sempre vista como uma sucessão sedimentar monótona, dominada por pelitos de coloração escura, possui história deposicional dinâmica e complexa. Esse artigo foi publicado pelo periódico Journal of South American Earth Sciences (http://dx.doi.org/10.1016/j.jsames.2016.08.002), e representa uma ampliação da análise iniciada por Bondioli (2014) sobre depósitos da Formação Serra Alta, no âmbito do mesmo grupo de pesquisa.

O artigo contido no anexo 3, "CHEMOAUTOTROPH BIVALVES FROM A LATE PALEOZOIC COLD METHANE SEEP SYSTEM IN AN INTRAPLATE BASIN: A CASE STUDY FROM THE BRAZILIAN PERMIAN GONDWANA”, registra, pela primeira vez, possíveis depósitos gerados por exsudações de metano e a fauna de bivalves associada. A versão apresentada contém a primeira versão (rascunho) do artigo, visto que análises petrográficas mais detalhadas estão ainda em processamento em laboratório fora do Brasil (Friedrich-Alexander-University of Erlangen; Alemanha). Por essa razão, os dados estão sendo apresentados valorizando as imagens dos depósitos sedimentares e seus fósseis, mais do que o texto em versão final de publicação. Em razão da complexidade e ineditismo do tema se optou por aguardar os comentários e sugestões da banca, antes da redação final do 
manuscrito.

No artigo contido no anexo 4, "THE INTERPLAY BETWEEN EVENT AND BACKGROUND SEDIMENTATION AND THE ORIGIN OF FOSSIL-RICH CARBONATE CONCRETIONS: A CASE STUDY IN PERMIAN ROCKS OF THE PARANÁ BASIN, BRAZIL", é discutida a origem e os aspectos tafonômicos e sedimentológicos envolvidos na gênese dos níveis de concreções ricas em fósseis de moluscos bivalves, encontradas na Formação Serra Alta (Grupo Passa Dois, Bacia do Paraná, Brasil). Esse artigo foi publicado pelo periódico científico Lethaia (http://dx.doi.org/10.1111/let.12124), estando também relacionado ao estudo iniciado por Bondioli (2014).

Os artigos apresentados estão dispostos em sua formatação final, como exigido pelo periódico aos quais foram submetidos. 


\section{PARTE 4}

4. DISCUSSÃO 


\subsection{DiscuSSÃo SuCINTA}

\subsubsection{Sobre os Bivalves da Crise ANóXiCa da FormaÇão Irati (ANEXo 1)}

Moluscos bivalves são comuns nas assembleias fósseis encontradas em depósitos de águas rasas (formações Teresina e Rio do Rasto) do Permiano da Bacia do Paraná, Brasil, mas tendem a ser raros nas fácies sedimentares geradas em águas profundas (abaixo do nível de base de ondas de tempestades, formações Irati e Serra Alta) (Runnegar \& Newell, 1971; Simões et al., 1998, 2015). Especialmente na Formação Irati, as ocorrências de bivalves são particularmente incomuns e pouco estudadas (Beurlen, 1957; Kazubek \& Simões, 2002, 2003a, b; Rohn et al., 2003; Lages, 2004). Neste contexto, é notável a ocorrência de concentrações de conchas de bivalves em um intervalo situado na porção basal da unidade, Membro Taquaral, da Formação Irati, representado por depósitos de folhelhos negros gerados em condições de costa à fora (offshore), e substratos anóxicos a disóxicos. Essas concentrações incluem espécimes de bivalves tentativamente atribuídos a Runnegariella e Plesiocyprinella.

Nas concentrações estudadas, nenhuma concha foi encontrada em posição de vida, não havendo tão pouco evidencias de atividade intraestratal na matriz sedimentar. Os bivalves são, preferencialmente, representados por valvas desarticuladas $(94,30 \%, n=364)$ e, dentre as passiveis de identificar, as esquerdas predominam $(60 \%$, $\mathrm{n}=81$ ). Esses dados mostram enviesamento em favor das valvas esquerdas, sugerindo seleção das valvas durante a gênese da concentração fossilífera. Histogramas de frequência de tamanho mostram distribuição unimodal/bimodal, indicando seleção de tamanho (Anexo 1; Fig. 9). Pequenos fragmentos de conchas ( $>3 \mathrm{~mm})$, arredondados ou com arestas são muito abundantes em alguns pavimentos (Anexo 1; Fig. 8B), fato incompatível com as condições de águas calmas que devem ter prevalecido durante a deposição dos pelitos em que foram preservados. Dessa forma, os fragmentos de conchas parecem ter sido fragmentados em condições de águas mais rasas. Em resumo, as evidências apresentadas indicam que as conchas e fragmentos foram transportados de ambientes contemporâneos mais rasos e depositados em condições de costa à fora.

Dois modos principais de ocorrência foram identificados no intervalo de um metro em que as concentrações de bivalves são encontradas nos folhelhos da Formação Irati. No primeiro caso, as conchas estão preservadas dispersas e caoticamente orientadas na matriz sedimentar. Os bivalves se encontram completos ou fragmentados, 
sempre desarticulados (Anexo 1; Fig. 8E). Neste caso, as conchas devem ter sido retiradas de ambientes mais rasos por processos tracionais de fundo, como, por exemplo, correntes ou fluxos gerados por tempestades, e depositadas por decantação nas porções mais distais da bacia. No segundo caso, as conchas são abundantes e formam pavimentos compostos por conchas inteiras ou pequenos fragmentos (Anexo 1; Fig.8AB). Nos pavimentos, as conchas estão preferencialmente desarticuladas, mas podem ser encontradas articuladas fechadas ou abertas $(5,7 \%, \mathrm{n}=22)$. Em direção ao topo do pacote, os pavimentos apresentam maior abundância e aumento na taxa de fragmentação.

Nas análises tafonômicas, a taxa de articulação em uma dada assembleia, é geralmente utilizada como evidência para o transporte das conchas e tempo de residência na interface água/sedimento (Brett \& Baird, 1986). Porém, diversos autores têm demonstrado que conchas de bivalves podem ser transportadas articuladas fechadas por longas distâncias (Sörlin, 1988; Cadée, 2002; Hunt et al., 2007; Fürsich et al., in press). Nas concentrações estudadas, os raros bivalves encontrados articulados fechados devem ter sido transportados vivos, morrendo no ambiente deposicional, anóxico ou disóxico (Anexo 1; Fig. 11B). As conchas encontradas articuladas abertas nos pavimentos podem representar conchas que estavam mortas e articuladas fechadas no ambiente original e que foram abertas durante o transporte (Watkins, 1974) (Anexo 1; Fig. 11B). Essas podem representar, também, indivíduos que foram transportados vivos e que morreram logo após a deposição em ambientes distais, ficando expostos por curtos períodos de tempo na interface água/sedimento, antes do soterramento final (Anexo 1; Fig. 11B). A ocorrência de bivalves articulados abertos é comum em sedimentos não bioturbados, depositados sob condições anóxicas/disóxicas, que favorecem a decomposição lenta dos ligamentos (Plotnick, 1986; Allison \& Briggs, 1991).

É importante notar que as conchas articuladas ou desarticuladas estão com o plano de comissura concordante ao plano de acamamento e predominantemente com a convexidade orientada para cima (Anexo 1; Figs. 8A). Em adição, medidas de direção em planta de centenas de conchas mostram a existência de orientação preferencial do maior comprimento das conchas (Anexo 1; Fig. 9). Essas características indicam que após a deposição das conchas por decantação, estas foram submetidas às correntes de 
fundo, responsáveis pela por sua reorientação (convexidade para cima e perpendiculares à orientação das paleocorrentes) (Anexo 1; Fig. 11C).

Finalmente, os pavimentos ricos em bivalves da Formação Irati são o produto final de diferentes processos sedimentares combinados, incluindo eventos episódicos de alta energia (e.g., correntes ou fluxos de tempestades), seguidos pela ação de eventos do dia-a-dia (e.g., correntes de fundo de longa duração), em condições de águas calmas, fundos anóxicos à disóxicos em ambiente plataformal (costa à fora) (Anexo 1; Fig. 11).

$\mathrm{Na}$ sucessão estudada, são registrados ao menos, três ciclos de granocrescência ascendente, aqui interpretados como produto de pulsos regressivos. A diminuição da espessura de cada ciclo em direção ao topo configura uma tendência progradacional ao longo da sucessão, que culmina com as fácies carbonáticas do Membro Assistência (Anexo 1; Fig.5). O intervalo rico em fósseis esta situado no topo do primeiro ciclo (Ciclo 1), onde os pavimentos de conchas estão alternados a pelitos afossilíferos, indicando deposição cíclica (Anexo 1; Fig.5). Neste contexto, o aumento na granulometria da rocha em cada ciclo e a presença do nível rico em fósseis é interpretado como produto do transporte de sedimentos proximais e organismos de porções mais rasas da bacia, provavelmente por correntes episódicas, geradas por eventos de alta energia, durante períodos de queda no nível de base.

A presença de bivalves na Formação Irati tem importantes implicações no entendimento da evolução da malacofauna endêmica do Permiano da Bacia do Paraná, Grupo Passa Dois. Runnegar \& Newell (1971) foram os primeiros a demonstrar que esses bivalves pertencem, maiormente, às famílias Pachydomidae (=Megadesmidae) e Astartidae. Posteriormente, Simões et al. (1997) demonstraram que todos os bivalves Pachydomidae eram endêmicos do Grupo Passa Dois e pertenceriam ao grupo monofilético Plesiocyprinellinae. Esses são aparentados a formas marinhas (Runnegar \& Newell, 1971; Simões et al., 1997). Por muitos anos, a maior objeção ao modelo de evolução endêmica formulado por Runnegar \& Newell (1971), para os bivalves do Passa Dois dizia respeito à completa ausência de bivalves na Formação Irati. Simões (1992) registrou a presença de bivalves marinhos gondwânicos (i.e. Megadesmus, Pyramus e Astartila) na Formação Palermo, situada abaixo da Formação Irati, indicando assim, que um estoque marinho de bivalves Pachydomidae colonizou a Bacia do Paraná antes do evento euxínico que marca a Formação Irati. 
Bivalves Pachydomidae são diversos e abundantes na Formação Teresina e por serem encontrados, muitas vezes, in situ em depósitos gerados em águas rasas devem ter colonizado fundos sob tais condições (Simões \& Kowalewski, 1998; Simões et al., 1998). Consequentemente é razoável assumir que seus ancestrais devem, igualmente, ter habitado ambientes marginais rasos, na Bacia do Paraná durante os tempos pré-Teresina (Runnegar \& Newell, 1971, p. 15). Os dados obtidos nesse estudo, corroboram esta hipótese, posto que bivalves de águas rasas (Runnegariella e Plesiocyprinella) foram identificados nas concentrações estudadas (Anexo 1; Fig.10). Esses bivalves provavelmente viveram em ambientes proximais contemporâneos a Formação Irati, onde poderiam ter sobrevivido ao episódio euxínico (veja Runnegar \& Newell, 1971). É importante notar que o gênero Plesiocyprinella é proximamente relacionado à Megadesmus (Simões et al., 1997), o qual ocorre na Formação Palermo (Simões, 1992). Finalmente, Plesiocyprinella é agora o representante conhecido mais antigo dos Pachydomidae do Grupo Passa Dois. É notável observar que, mesmo na ausência desses dados, Runnegar \& Newell (1971) postularam um modelo evolutivo para os bivalves do Grupo Passa Dois, que mostra-se hoje muito plausível. Nesse contexto, um dos aspectos mais relevantes dos dados obtidos é o de que as malacofaunas permianas da Bacia do Paraná se desenvolveram continuamente entre as formações Rio Bonito e Palermo (Grupo Guatá), abaixo, e as formações Irati e Serra Alta (Grupo Passa Dois), acima (veja também Simões, 1992).

\subsubsection{Sobre os Estudos Realizados na FormaÇÃo Serra Alta (AneXos 2, 3 E}

4)

Assim como na sucessão estratigráfica estudada na Formação Irati, a da Formação Serra Alta, sobreposta, é constituída predominantemente por depósitos plataformais, gerados em condições de costa à fora, onde a decantação de finos foi o processo predominante de sedimentação (Warren et al., 2015). Por essa razão a Formação Serra Alta foi interpretada, à primeira vista, como uma sucessão monótona, pobre em fósseis e depositada sob condições transgressivas, com fundos predominantemente pobres em oxigênio. Porém a análise integrada (sedimentológica, tafonômica e paleontológica) de afloramentos (Anexo 2; Fig. 2) situados no km 160,7 da Rodovia Castello Branco, região de Porangaba-SP (Anexo 2; Fig. 1) demonstra que os depósitos de costa à fora dessa unidade têm uma história sedimentar bastante dinâmica e 
complexa, como indicado pela presença de (a) vários depósitos de sufocamento (obrution deposits), contendo conchas de bivalves; (b) arenitos finos com estratificação cruzada do tipo swaley; (c) diques clásticos e rochas carbonáticas brechadas com estruturas do tipo flame e (d) camadas com nódulos fosfáticos, à moda de bone-beds intercaladas em siltitos maciços. De fato, o estudo detalhado de uma sucessão de 11 metros, contendo argilitos predominantemente maciços registra variações em diversos parâmetros ambientais, sendo o mais óbvio deles a oxigenação de fundo, as taxas de sedimentação e variações na profundidade relativa da lâmina d'água. A variação desses parâmetros é refletida na abundância, diversidade e composição faunística das assembleias de bivalves.

Ao longo da seção estudada, bioturbações e traços fósseis são registrados de forma difusa, ocorrendo em altas ou baixas densidades em certos intervalos estratigráficos. De modo geral, o índice de bioturbação é baixo e Planolites é o traço mais comumente observado. A presença de traços de águas rasas (e.g., Planolites), em condições relativamente profundas é uma característica típica da colonização oportunista do substrato por comunidades de invertebrados bentônicos desenvolvidas sob condições de stress ambiental (Ekdale, 1985; Hoffmann \& Krobicki, 1989; Buatois et al., 2011; Boyer \& Droser, 2011). No siltito cinza escuro maciço, predominante na seção estudada (vide Anexo 2; Fig. 3A-B), o índice de bioturbação varia de 0 a 1 e as conchas de bivalves estão ausentes. Os traços se tornam mais abundantes e os sedimentos altamente bioturbados quando associados às camadas geradas por processos episódicos de alta energia. São elas: (a) camada de arenito síltico silicificado, altamente bioturbado (BI-4) que contém traços de Planolites centimétricos na base e milimétricos no topo (Anexo 2; Fig. 4B). Essa feição pode indicar variações nas taxas de oxigenação durante a deposição desses sedimentos, sendo que as maiores concentrações desse elemento devem estar associadas ao intervalo com os traços maiores. Em seção, os tubos estão compactados indicando que os traços foram gerados em substrato incoerente, saturado em água. (b) camada de arenito com estratificação cruzada do tipo swaley, com topo altamente bioturbado (Anexo 2; Fig. 4A). Essas características indicam que a atividade bentônica foi intensa durante os momentos de diminuição das taxas de sedimentação e melhoria nas condições de oxigenação de fundo, após a deposição dos arenitos por processos sedimentares de alta energia (veja, por exemplo, Buatois et al., 2011). (c) camada de calcário brechado, com Thalassinoides e Planolites na base (Anexo 2; Fig. 5), registrando, novamente, a colonização oportunista do substrato pelos organismos bentônicos de infauna, provavelmente, sob condições 
disaeróbias e baixas taxas de sedimentação (Boyer \& Droser, 2011). Finalmente, todos os eventos de colonização bentônica oportunista registrados são sucedidos por siltitos maciços (BI-0-1), afossilíferos, que registram o retorno das condições de sedimentação do dia-a-dia, marcados pelo predomínio da decantação de finos, em fundos pobres em oxigênio (Anexo 2; Fig. 3A-B).

Finalmente, a camada de nódulos fosfáticos (Anexo 2; Fig. 6) registrada no topo da seção é mais um indicativo dos processos dinâmicos envolvidos na gênese da sucessão estudada (Anexo 2; Fig. 6). Conforme discutido por Brett \& Baird (1986), o processo de fosfatização é comum aos ambientes restritos, ricos em matéria orgânica. De acordo com esses autores, o soterramento abrupto da matéria orgânica, seguido por um período de sedimentação mínima ou não deposição, às vezes com subsequente erosão dos sedimentos já depositados, constitui condição primordial para a fosfatização. O modelo para a geração de fosfatos e camadas fosfáticas condensadas, proposto por Föllmi et al. (1991) e John et al. (2002) é cabível no caso da Formação Serra Alta, aqui discutido. Inicialmente, a fosfatogênese tem início em com fundo anóxico, rico em matéria orgânica (incluindo pirita), com fragmentos de ossos e restos orgânicos. Esses constituem o núcleo para geração das partículas fosfáticas. Subsequentemente, processos de seleção concentram os nódulos por tamanho, os quais podem ser recobertos por fosfato se as condições para fosfatização permanecerem. Tem-se assim uma camada distinta de nódulos fosfáticos, os quais podem ser recobertas novamente. Durante eventos de alta energia, o retrabalhamento das partículas fosfatizadas e a quebra de camadas coesas de fosfato poderá ocorrer, seguidos por transporte e redeposição dessas partículas. Posteriormente, os nódulos fosfáticos retrabalhados, novos bioclastos e intraclastos poderão servir como elementos para nucleação de novos nódulos fosfáticos. A natureza amalgamada da camada de nódulos fosfáticos estudada, a presença de bioclastos não recobertos por nódulos fosfáticos em associação com nódulos de diferentes dimensões (Anexo 2; Fig. 6C), a presença de intraclastos e a base brusca e erosiva da camada, evidenciam que o processo descrito acima pode ter se repetido por diversas vezes (Föllmi et al., 1991; John et al., 2002). Importante observar que essa camada amalgamada, com base erosiva é indicativa de mudanças no nível de base, com queda episódica do nível do mar, em um depósito plataformal.

Outro aspecto que chama a atenção na seção estudada da Formação Serra Alta, é a distribuição vertical e lateral dos fósseis corpóreo. Esses são representados por 
uma fauna pouco diversificada de moluscos bivalves endêmicos. Conforme já discutidos acima, a escassez da fauna bentônica nas porções basais da Formação Serra Alta está provavelmente relacionada a condições de estresse ambiental devido ao predomínio de condições de baixas concentrações de oxigênio.

Nas porções mais basais da sucessão estudada (Anexo 2; Fig.7A), ocorrem conchas pequenas (geralmente milimétricas), muitas vezes articuladas (abertas ou fechadas), sem sinais de abrasão ou bioerosão (Anexo 2; Fig. 7C-E). São interpretadas como (elementos autóctones ou parautóctones (sensu Kidwell et al., 1986). Essas conchas pertencem a espécies de infauna, suspensívoras, tais como Barbosaia angulata e Rioclaroa lefevrei e devem representar táxons adaptados a condições de baixa concentração de oxigênio. Seriam os elementos pioneiros de comunidades bentônicas pouco diversificadas, capazes de prosperar em condições disóxicas (veja Kauffman \& Sageman, 1990). Consequentemente, sua ausência em certos intervalos, onde predominam siltitos maciços deve indicar completa anoxia ou condições extremamente disóxicas (Anexo 2; Fig.7B).

A ocorrência e abundância de conchas grandes (gigantes) de bivalves, alguns com feições morfologicas incomuns, incluindo Tambaquyra camargoi, Anhembia froesi e Maackia contorta (Mendes, 1952; Simões et al., 1998; 2000a, b) é uma feição marcante do intervalo geológico estudado da Formação Serra Alta (Anexo 2; Fig. 8C-E). Estas espécies estão preservadas tipicamente em dois horizontes bem definidos, no interior de concreções carbonáticas (Bondioli et al., 2015) associadas a siltitos cinza escuros maciços (Anexo 2; Fig. 8A) (Simões et al., 2000b; Bondioli et al., 2015). Alguns autores sugerem que Tambaquyra e Anhembia são bons candidatos permianos a serem bivalves quimiossimbiontes (Ghilardi, 1999; Ghilardi \& Simões, 2000, 2002; Matos et al., 2013), assunto retomado logo abaixo.

\subsubsection{Foram os bivalves da Formação Serra Alta elementos quimiossimbiontes que viveram associados a sistema de exsudação de metano em uma bacia intracratônica?}

As características observadas no intervalo estratigráfico analisado da Formação Serra Alta, incluindo (a) concreções carbonáticas ricas em fósseis e camadas de calcário brechado com valores de $\delta^{13} \mathrm{C}$ negativos, associadas a diques clásticos e 
fraturas, (b) conchas de bivalves com grandes dimensões e feições morfológicas incomuns, também com valores de $\delta^{13} \mathrm{C}$ negativos, (c) ocorrências de pavimentos densos de conchas de bivalves grandes, preservados na base de estruturas dômicas (=mounds), (d) em fácies predominantemente argilíticas pobremente fossilíferas, poucos metros acima da Formação Irati, podem ser explicadas pela existência de um sistema de exsudações de metano/óleo em um ambiente de costa à fora, anóxico a disóxico (veja também Alessandretti et al., em preparação).

Durante a deposição dos argilitos pobres em fósseis da Formação Serra Alta prevaleceram condições de baixa oxigenação de fundo, incapazes de sustentar grande diversidade de invertebrados. De fato, evidências tafonômicas e sedimentológicas indicam que os gêneros Anhembia, Tambaquyra e Maackia viveram em substrato mole, em fundos quase estagnados, pobres em oxigênio (veja também Simões et al., 1998, 2000a,b, in press; Bondioli et al., 2015). O desenvolvimento de concreções carbonáticas com valores negativos de $\delta^{13} \mathrm{C}$, coincide com a presença de abundantes bivalves da assembleia de moluscos contendo conchas de Anhembia, Tambaquyra e Maackia, aqui referida como assembleia ATM (Simões et al., 2000b; Bondioli et al., 2015). Notavelmente, as conchas desses bivalves são grandes em comparação às formas coevas de fácies oxigenadas, encontradas nas formações Teresina e Corumbataí (Anexo 3; Fig.11). Cada um dos gêneros que compõem a assembleia-ATM apresenta características morfológicas distintas e não usuais, associadas a especializações ecológicas relativas à vida em ambientes pobres em oxigênio. T. camargoi é o maior dentre os bivalves endêmicos permianos da Bacia do Paraná, apresentando as dimensões máximas de 100,45 mm de comprimento e 90,60 mm de altura. Suas dimensões contrastam fortemente com as registradas para outros bivalves do Grupo Passa Dois, os quais raramente apresentam dimensões maiores que $48,4 \mathrm{~mm}$ de comprimento e 39,3 mm de altura. Em adição, conchas de T. camargoi podem ser 10 vezes maiores que os demais bivalves que ocorrem nos argilitos do intervalo estudado, na Formação Serra Alta. Conchas de T. camargoi são raramente encontradas em arenitos ricos em bioclastos das fácies proximais, oxigenadas da Formação Teresina. Quando associadas a essas condições, suas dimensões não ultrapassam $40 \mathrm{~mm}$ de comprimento e $35 \mathrm{~mm}$ de altura (veja Simões \& Kowalewski, 1998). Na verdade, conchas dessa espécie são comuns apenas na porção basal da Formação Serra Alta, onde prevalecem argilitos escuros, depositados em fácies de costa à fora, pobres em fósseis (Bondioli, 2014; 
Bondioli et al., 2015; Warren et al., 2015), sendo particularmente abundantes nos intervalos onde ocorrem concreções carbonáticas e calcários brechados. Notavelmente, conchas de T. camargoi mantém suas grandes dimensões nessas fácies sedimentares, e se tornam ainda mais abundantes na base de estruturas dômicas (=mounds) (Anexo 3; Fig. 6). Nessas condições, 50 espécimes de T. camargoi formam uma concentração densa de conchas articuladas fechadas. A presença de diferentes classes de tamanho indica que diferentes gerações colonizaram a base de estruturas dômicas.

As demais espécies da assembleia ATM, que correm associadas à $T$. camargoi, possuem feições morfologicas muito distintivas. Por exemplo, A. froesi possui, na porção anterior da concha, rostrum pronunciado, semelhante ao encontrado em conchas de Arconaia lanceolata (veja Runnegar \& Newell, 1971, p. 146), um bivalve quimiossimbionte vivente (Savazzi \& Yao, 1992). A distribuição dessa espécie é também limitada à parte basal da Formação Serra Alta. Finalmente, as conchas de $A$. froesi encontradas no interior de concreções carbonáticas apresentam valores negativos de $\delta^{13} \mathrm{C}$ (Anexo 3; Tabela 1). Por outro lado, M. contorta apresenta torção das valvas (sensu McGhee, 1978; Savazzi, 1981), condição caracterizada pela torsão do plano de comissura ao longo do eixo da charneira. De acordo com Savazzi (1984, p.307), a torsão das valvas eleva a região posterior da concha acima do substrato, alinhando-a horizontalmente. Assim como M. contorta, os demais bivalves que apresentam torsão de valva, atuais ou fósseis, são encontrados em depósitos de sedimentos finos, ricos em $\mathrm{H}_{2} \mathrm{~S}$, gerados em condições de águas calmas, pobres em oxigênio (Seilacher, 1990, p. 302). Esse autor sugere que os bivalves que apresentam esta condição são quimiossimbiontes. Neste caso, a torção da comissura pode deixar os órgãos inalantes próximos do substrato, permitindo que eles se beneficiem da fonte $\mathrm{de}_{2} \mathrm{H}_{2} \mathrm{~S}$ disponível no sedimento (Seilacher, 1990, p. 302).

Os bivalves da assembleia ATM possuem clara preferência pelas fácies exaeróbias/disaeróbias da Formação Serra Alta (Anexo 3; Fig.12) e a produção e manutenção de conchas de grandes dimensões envolve a necessidade de fontes alternativas de energia (i.e., hidrocarbonetos). Em suma, evidências como, morfologias incomuns, grandes dimensões, distribuição preferencial em determinadas fácies sedimentares (i.e., costa à fora pobre em oxigênio), associação com calcários brechados e estruturas dômicas, todos com valores negativos de $\delta^{13} \mathrm{C}$, sugerem, fortemente, modo de vida quimiossimbionte para esses bivalves (ao menos de forma facultativa). 
Nesse contexto, é importante questionar qual seria a fonte de hidrocarbonetos que alimentaria as relações quimiossimbiontes da assembleia ATM. Em sistemas onde ocorrem exalações ativas de hidrocarbonetos, os líquidos e gases são originados vários metros (ou mesmo quilômetros) abaixo da interface água-sedimento, via degradação da matéria orgânica por altas temperaturas ou oxidação anaeróbia do metano, processo metabólico mediado por archeas metanotróficas e bactérias redutoras de sulfatos. Em locais onde hidrocarbonetos estão disponíveis em grandes quantidades, ou quando as tensões tectônicas comprimem pilhas de sedimentos ricos em matéria orgânica, fluidos podem subir através de sistemas de fraturas e fissuras. Em alguns ambientes marinhos, óleos também podem fluir através de fraturas, formando um sistema de exsudação de óleos.

No registro geológico paleozoico da Bacia do Paraná, os folhelhos betuminosos permianos da Formação Irati podem ter contribuído para o sistema de exsudações de metano e/ou outros hidrocarbonetos preservado na Formação Serra Alta. A Formação Irati é mundialmente conhecida pelo seu alto teor de matéria orgânica, maior que 23\% (COT) (Zalán et al., 1990; Milani \& De Wit, 1998). Como mostrado na Figura 2 no Anexo 3, o intervalo onde são encontrados as estruturas dômicas, na Formação Serra Alta esta a poucos metros acima do contato com a Formação Irati. Consequentemente, a sucessão rica em óleo abaixo do intervalo analisado pode ter atuado como fonte de metano e/ou outros hidrocarbonateos, que teria se propagado de forma difusa ou através de fissuras e fraturas (Anexo 3; Fig.13) possivelmente geradas por tectônica sinsedimentar. De fato, os baixos conteúdos de matéria orgânica apresentados pela Formação Serra Alta (Teixeira, 2014) indicam que os hidrocarbonetos que alimentaram o sistema não podem ter sido gerados pelos sedimentos dessa unidade.

Os valores negativos de $\delta^{13} \mathrm{C}$ de conchas, do calcário brechado e do argilito altamente bioturbado que forma as estruturas dômicas (Tabela 1) indicam que os moluscos bivalves viveram junto a um sistema de exsudações de metano e/ou outros hidrocarbonetos (veja Peckmann \& Thiel, 2004; Kiel \& Peckmann, 2007, para um exemplo similar). Entretanto, os valores "pouco negativos" (por volta de $-7 \%$ ) dos carbonatos estudados, revelam que parte do carbono, deve ter derivado de matéria orgânica. No Golfo do México, carbonatos atuais, que estão se formando em sistemas de exsudações de óleo, sob altas taxas de exsudação apresentam valores de $\delta^{13} \mathrm{C}$ variando entre-25 e -15\% (Joye et al., 2004, Kiel \& Peckmann, 2007). Porém, sob 
baixas taxas de exsudação os valores são maiores, por volta de -10\%o (Joye et al., 2004). Notavelmente, nas Montanhas Wagonwheel, California, carbonatos cenozóicos gerados em um sistema de exsudações de hidrocarbonetos apresentam valores de $\delta^{13} \mathrm{C}$ entre 12.2 e -5.0\%o, "indicando exalações de óleo e não de metano" (Kiel \& Peckmann, 2007). Os valores obtidos para o carbonato e estruturas dômicas do intervalo estudado da Formação Serra Alta estão dentro da amplitude encontrada por Kyel \& Peckmann (2007), sugerindo a existência de processos difusos de exsudações de metano e/ou outros hidrocarbonetos.

Em resumo, as informações tafonômicas, sedimentológicas e estratigráficas associadas aos dados isotópicos indicam que o sistema de exsudações de hidrocarbonetos da Formação Serra Alta era complexo (Anexo 3; Figs. 13, 14). O brechamento do calcário pode estar relacionado ao escape de gás metano (veja Nobuhara, 2003), o qual depende da disponibilidade desse hidrocarboneto e das condições de temperatura e pressão na subsuperfície do pacote de sedimentos ricos em matéria orgânica (= Formação Irati). Em nosso estudo de caso, os diques clásticos, fissuras/fraturas e estruturas de injeção associadas ao intervalo em que ocorrem as estruturas dômicas, devem ter atuado como sistema de condução para o metano e/ou outros hidrocarbonetos (Anexo 3; Fig.13) (veja Alessandretti et al., in prep.). Apesar de estar presente na unidade imediatamente subjacente (= Formação Irati), a presença de pirobetume não é registrada em associação ao calcário brechado ou os argilitos coevos da Formação Serra Alta. Uma possível explicação para este fato, seria a evaporação do óleo através da superfície da água e/ou seu transporte pelas correntes marinhas caso esse fosse leve (Anexo 3; Fig. 13) (veja Woods Hole Oceanographic Institution, 2014).

Os dados apresentados possuem importantes implicações para a história evolutiva da quimiossimbiose dentro dos Anomalodesmata. A quimiossimbiose nos moluscos bivalves é bem conhecida nas famílias Lucinidae, Manzanellidae, Mytilidae, Nucinellidae; Solemyidae, Teredinidae, Thyasiridae e Vesicomyidae (Distel, 1998; Taylor \& Glover, 2010; Duperron et al., 2012; Roeselers \& Newton, 2012; Oliver \& Taylor, 2012), as quais abrigam nos seus tecidos bactérias oxidantes de enxofre e/ou metanotróficas (Dubilier et al., 2008; Vrijenhoek, 2010; Anderson, 2014). Como observado por Anderson (2014), a história evolutiva e os relacionamentos desses grupos de bivalves com as bactérias que eles hospedam indicam que a quimiossimbiose evoluiu repetidamente em diferentes membros da Classe Mollusca (Anderson, 2014, p. 50). O 
mesmo parece ter ocorrido com os bivalves permianos endêmicos da Formação Serra Alta. De fato, apesar das incertezas com relação à posição sistemática dos gêneros Anhembia e Maackia dentro dos Anomalodesmatas, eles são geralmente atribuídos ao clado endêmico Pachydomiidae (anteriormente referidos aos Megadesmidae, veja Runnegar \& Newell, 1971; Simões et al., 1997; Mello, 1999), grupo em que se encontra também o gênero Tambaquyra. A complexa história evolutiva desse grupo e suas radiações adaptativas extremas na Bacia do Paraná foram detalhadamente documentadas por Beurlen (1954), Runnegar \& Newell (1971), e Simões et al. (1998). Após o evento euxínico registrado pela Formação Irati, esse grupo de bivalves suspensívoros de infauna rasa irradiaram e colonizaram diferentes regiões da bacia, desde as fácies sedimentares mais rasas (oxigenadas) até as mais profundas (predominantemente disóxicas) (Simões et al., 1998). Eventualmente, durante essas irradiações adaptativas, bivalves endêmicos se adaptaram e colonizaram os ambientes de costa á fora, lamosos, disaeróbios a exaeróbios, onde o metano e outros hidrocarbonetos, assim como sulfatos associados a esse sistema, eram a principal fonte de energia.

\subsection{REFERÊNCIAS BIBLIOGRÁFICAS}

ALESSANDRETTI, L. et al. (em preparação) A singular Permian methane seep system in the Paraná Basin revealed by clastic dykes and fossil-rich carbonate concretions.

ALLISON, P.A. \& BRIGGS, D.E.G. (1991) Taphonomy: Releasing the data locked in the fossil record. Plenum, New York.

ANDERSON, L.C. (2014) Relationships of internal shell features to chemosymbiosis, life position, and geometric constraints within the Lucinidae (Bivalvia). In: HEMBREE, D.I., PLATT, B.F. \& SMITH, J.J. (Eds.) Experimental Approaches to Understanding Fossil Organisms. Lessons from the Living, Topics in Geobiology, Springer, 41: 49-72.

BEURLEN, K. (1954) As faunas de lamelibrânquios do sistema gonduânico no Paraná. In: LANGE, F.W. (Ed.) Volume comemorativo do $1 .^{o}$ Centenário do Estado do Paraná. Curitiba, 107-136. 
BEURLEN, K. (1957) Um lamelibrânquio do Folhelho Irati de São Mateus do Sul, Estado do Paraná. Notas Preliminares e Estudos. Divisão de Geologia e Mineralogia, 98: 1-5.

BONDIOLI, J.G. (2014) Dinâmica sedimentar, tafonomia e paleoambientes da facies de offshore da Formacão Serra Alta, Permiano, Bacia do Paraná: um estudo de caso no Estado de São Paulo, Brasil. 130 pp. Dissertação de Mestrado, Instituto de Geociências, USP, 130pp.

BONDIOLI, J.G., MATOS, S.A., WARREN, L.V., ASSINE, M.L., RICCOMINI, C. \& SIMÕES M.G. (2015) The interplay between event and background sedimentation and the origin of fossil-rich carbonate concretions: a case study in Permian rocks of the Paraná Basin, Brazil. Lethaia, 48: 522-539.

BOYER, D.L. \& DROSER, M.L. (2011) A combined trace and body fossil approach reveals high resolution record of oxygen fluctuations in Devonian seas. Palaios, 26: $500-508$.

BRETT, C.E. \& BAIRD, G.C. (1986) Comparative taphonomy: a key to paleoevironmental interpretation based on fossil preservation. Palaios, 1: 207-227.

BUATOIS, L.A., SACCAVINO, L.L. \& ZAVALA, C. (2011) Ichnologic signatures of hyperpycnal flow deposits in Cretaceous river-dominated deltas, Austral Basin, southern Argentina. In: SLATT, R.M. \& ZAVALA, C. (Eds.) Sediment transfer from shelf to deep water-Revisiting the delivery system. Studies in Geology. AAPG, Tulsa, 61: 153-170.

CADÉE, G.C. (2002) Floating articulated bivalves, Texel, North Sea. Palaeogeography, Palaeoclimatology, Palaeoecology, 183: 355-359.

DISTEL, D.L. (1998) Evolution of Chemoautotrophic Endosymbioses in Bivalves. BioScience, 48(4): 277-286.

DUBILIER, N., BERGIN, C. \& LOTT, C. (2008) Symbiotic diversity in marine animals: the art of harnessing chemosynthesis. Nature Reviews Microbiology, 6: 725-740.

DUPERRON, S., RODRIGUES, C.F., LEGER, N., SZAFRANSKI, K.M., DECKER, C., OLU, K. \& GAUDRON, S.M. (2012) Diversity of symbioses between chemosynthetic bacteria and metazoans at the Guiness cold seep site (Gulf of Guinea,West Africa). Microbiology Open, 1: 467-480. 
EKDALE, A.A. (1985) Paleoecology of the marine benthos. Palaeogeography, Palaeoclimatology, Palaeoecology, 50: 63-81.

FÖLLMI, K.B., GARRISON, R.E. \& GRIMM, K.A. (1991) Stratification in Phosphatic Sediments: Illustration from the Neogene of California. In: EINSELE, G., RICKEN, W. \& SEILACHER, A. (Eds.) Cycles and Events in Stratigraphy. Springer Verlag, Berlin-Heidelberg, p. 493-507.

FÜRSICH, F.T., PAN, Y.H. \& WANG, Y.Q. (in press) Biostratinomy of bivalves from Jurassic and Early Cretaceous lakes of NE China. Palaeoworld.

GHILARDI, R.P. (1999) Paleoautoecologia dos bivalves do Grupo Passa Dois (Neopermiano) no Estado de São Paulo: bivalves fósseis como indicadores da dinâmica sedimentar. Dissertação de Mestrado. Instituto de Geociências, USP 160pp.

GHILARDI, R.P. \& SIMÕES, M.G. (2000) Permian megadesmids (Bivalvia, Anomalodesmata) as Paleozoic candidates to be chemosymbiotic bivalves. In: XXXI International Geological Congress. Rio de Janeiro, Proceedings, CD-room.

GHILARDI, R.P. \& SIMÕES, M.G. (2002) Foram os bivalves do Grupo Passa Dois (exclusive Formação Rio do Rasto), Neopermiano, invertebrados tipicamente dulcícolas? Pesquisas em Geociências, 29: 3-13.

HOFFMANN, M. \& KROBICKI, M. (1989) Oyster buildup within the dysaerobicfacies mudstones (Middle Jurassic, central Poland) - example of benthic island colonization. Annales Societatis Geologorum Poloniae, 59: 299-330.

HUNT, H.L., MALTAIS, M.J., FUGATE, D.C. \& CHANT, R.J. (2007) Spatial and temporal variability in juvenile bivalve dispersal: effects of sediment transport and flow regime. Marine Ecology Progress Series, 352: 145-159.

JOHN, C.M. FÖLlMI, K.B., KAENEL, E., ADATTE, T., STEINMANN, P. \& BADERTSCHER, C. (2002) Carbonaceous and phosphate-rich sediments of the Miocene Monterey Formation at El Capitan State Beach, California, U.S.A. Journal of Sedimentary Research, 72: 252-267.

JOYE, S.B., BOETIUS, A., ORCUTT, B.N., SCHULZE, H.N., MONTOYA, J.P., ERICKSON, M.J. \& LUGO, S.K. (2004) The anaerobic oxidation of methane and sulfate reduction in sediments from Gulf of Mexico cold seeps. Chemical Geology, 205: 219-238. 
KAUFFMAN, E.G. \& SAGEMAN, B.B. (1990) Biological sensing of benthic environments in dark shales and related oxygen-restricted facies. In: GINSBURG, R.N. \& BEAUDOIN, B. (Eds.) Cretaceous Resources, Events, and Rhythms. Kluwer Press, Amsterdam, p. 125-138.

KAZUBEK, M.F., \& SIMÕES, M.G. (2002) The lost fauna unearthed: Permian bivalves of the Irati Formation (Passa Dois Group), Paraná Basin, Brazil. In: Paleo - 2002, Porto Alegre, Paleontologia em Destaque, 40: 31.

KAZUBEK, M.F. \& SIMÕES, M.G. (2003a) Permian bivalves of the Irati Formation (Passa Dois Group, Paraná Basin) and their paleoecological significance. In: XVIII Congresso Brasileiro de Paleontologia, Brasília, Boletim de Resumos, 1: 161.

KAZUBEK, M.F. \& SIMÕES, M.G. (2003b) Feições sedimentológicas, bioestratinômicas e estratigráficas das concentrações de bivalves do Membro Taquaral (Formação Irati, Grupo Passa Dois, Bacia do Paraná) e seus significados. In: Paleo-2003, Curitiba, Paleontologia em Destaque, 44: 29.

KIDWELL, S.M., FÜRSICH, F.T. \& AIGNER T. (1986) Conceptual framework for the analysis of fossil concentrations. Palaios, 1: 228-238.

KIEL, S. \& PECKMANN, J. (2007) Chemosymbiotic bivalves and stable carbon isotopes indicate hydrocarbon seepage at four unusual Cenozoic fossil localities. Lethaia, 40(4): 345-357.

LAGES, L.C. (2004) A Formação Irati (Grupo Passa Dois, Permiano, Bacia do Paraná) no furo de sondagem FP-01-PR (Sapopema, PR). Dissertação de mestrado. Instituto de Geociências e Ciências Exatas. Universidade Estadual Paulista, UNESP, $117 \mathrm{pp}$.

MATOS, S.A., BONDIOLI, J.G., DAVID, J.M., ANELLI, L.E., WARREN, L.V., RICCOMINI, C. \& SIMÕES, M.G. (2013) Paleoecology of 'giant' Plesiocyprinellini (Tambaquyra) bivalves on Permian epeiric seafloors in the Paraná Basin, Brazil. In: XXIII Congresso Brasileiro de Paleontologia Paleontologia em Destaque. Gramado, Boletim de Resumos, p. 194-195.

MCGHEE, G.R. (1978) Analysis of the shell torsion phenomenon in the Bivalvia. Lethaia, 11(4): 315-329.

MELLO, L.H.C. (1999) Análise cladística dos bivalves do Grupo Passa Dois (Neopermiano), Bacia do Paraná, Brasil: implicações taxonômicas, evolutivas e 
paleobiogeográficas. Dissertação de Mestrado. Instituto de Geociências, USP 160pp.

MENDES, J.C. (1952) A Formação Corumbataí na região do Rio Corumbataí. (Estratigrafia e descrição dos lamelibrânquios). Boletim da FCLF-USP, 145, Geologia, 8: 1-119.

MILANI, E.J. \& DE WIT, M.J. (1998) Correlations between the classic Paraná and Cape-Karoo sequences of South America and southern Africa and their basin infills flanking the Gondwanides: Du Toit revisited. Geological Society of London, Special Publications, 294: 319-342.

NOBUHARA, T. (2003) Cold seep carbonate mounds with Vesicomya (Calyptogena) Kawamurai (Bivalvia: Vesycomyidae in slope mud facies of the Pliocene forearc basin of the Sagara-Kakegawa area, central Japan. Paleontological Research, 7: 313-328.

OLIVER, P.G. \& TAYLOR, J.D. (2012) Bacterial symbiosis in the Nucinellidae (Bivalvia: Solemyida) with description of two new species. Journal of Molluscan Studies, 78: 81-91.

PECKMANN, J. \& THIEL, V. (2004) Carbon cycling at ancient methane seeps. Chemical Geology, 205: 443-467.

PLOTNICK, R. (1986) Taphonomy of a modern shrimp: implications for the arthropod fossil record. Palaios, 1: 286-293.

ROESELERS, G. \& NEWTON, I.L.G. (2012) On the evolutionary ecology of symbioses between chemosynthetic bacteria and bivalves. Applied Microbiology and Biotechnology, 94: 1-10.

ROHN, R., LAGES, L.C. \& PENATTI, J.R.R. (2003) Litofácies da Formação Irati no furo de sondagem FP-01-PR (Permiano, borda leste da Bacia do Paraná). In: II Congresso Brasileiro de P\&D em Petróleo \& Gás, Rio de Janeiro, Resumos, 1: 1-6.

RUNNEGAR, B. \& NEWELL, N.D. (1971) Caspian- like relict moluscan fauna in the South America Permian. Bulletin of the American Museum of Natural History, 146: $1-66$.

SAVAZZI, E. (1981) Barbatia mytiloides and the evolution of shell torsion in arcid pelecypods. Lethaia, 14(2): 143-150.

SAVAZZI, E. (1984) Adaptive significance of shell torsion in mytilid bivalves. Palaeontology, 27: 307-304. 
SAVAZZI, E. \& YAO, P. (1992) Some morphological adaptations in freshwater bivalves. Lethaia, 25: 195-209.

SEILACHER, A. (1990) Aberrations in bivalve evolution related to photo- and chemosymbiosis. Historical Biology, 3: 289-311.

SIMÕES, M.G. (1992) Pelecípodes da Formação Palermo (Permiano) de São Sepé (RS) e Guiratinga (MT): implicações na evolução da fauna Neopaleozóica da Bacia do Paraná, Brasil. Tese de doutorado. Instituto de Geociências, Universidade de São Paulo, USP. 286pp.

SIMÕES, M.G. \& KOWALEWSKI, M. (1998) Shell beds as paleoecological puzzles: a case study from the Upper Permian of the Paraná Basin, Brazil. Facies, 38: 175196.

SIMÕES, M.G.; MARQUES, A.C.; MELLO, L.H.C. \& ANELLI, L.E. (1997) Phylogenetic analysis of the genera of the extinct Family Megadesmidae (Pelecypoda, Anomalodesmata), with remarks on its paleoecology and taxonomy. Journal of Comparative Biology, 2: 75-90.

SIMÕES, M.G.; ROCHA-CAMPOS, A.C. \& ANELLI, L.E. (1998) Paleoecology and evolution of Permian pelecypod assemblages (Paraná Basin) from Brazil. In: JOHNSTON, P.A. \& HAGGART, J.W. (Ed.) Bivalves - An Eon of evolution: paleobiological studies honoring Norman D. Newell. Calgary: University of Calgary Press, p. 443-452.

SIMÕES, M.G.; MELLO, L.H.; TORELLO, F.F. \& GHILARDI, R.P. (2000a) Tambaquyra gen.n. (Bivalvia, Anomalodesmata), Formação Serra Alta (Neopermiano), Grupo Passa Dois, Bacia do Paraná, Brasil. Revista Universidade de Guarulhos, Série Geociências, 6: 11-19.

SIMÕES, M.G.; TORELLO, F.F.; MELLO, L.H.C \& GHILARDI, R.P. (2000b) O conteúdo fossilífero de novos afloramentos do Grupo Passa Dois (Neopermiano), nas porções centro sul e nordeste do Estado de São Paulo: implicações bioestratigráficas e paleoecologicas. Acta Geologica Leopoldensia, 23: 61-90.

SIMÕES, M.G., MATOS, S. A., ANELLI, L.E., ROHN, R., WARREN, L.V. \& DAVID, J.M. (2015) A new Permian bivalve-dominated assemblage in the Rio do Rasto Formation, Paraná Basin, Brazil: Faunal turnover driven by regional-scale environmental changes in a vast epeiric sea. Journal of South American Earth Sciences, 64: 14-26. 
SIMÕES, M.G., MATOS, S.A., WARREN, L.V., ASSINE, M.L., RICCOMINI, C. \& BONDIOLI, J. G. (in press) Untold muddy tales: Revealing the paleoenvironmental dynamics of a "barren" mudrock sucession from a shallow Permian epeiric sea.

SÖRLIIN, T. (1988) Floating behaviour in the tellinid bivalve Macoma bMthica (L.). Oecologia, 77: 273-277.

TAYLOR, J.D. \& GLOVER, E.A. (2010) Chemosymbiotic bivalves. In: KIEL, S. (Ed.) The vent and seep biota - from microbes to ecosystems. Topics in geobiology. Heidelburg, Springer, 33: 107-135.

TEIXEIRA, C.A.S. (2014) Evolução térmica e paleofluidos dos folhelhos da formação Serra Alta na borda leste da Bacia do Paraná. Dissertação de Mestrado. Instituto de Geociências, USP, 80pp.

VRIJENHOEK, R.C. (2010) Genetic diversity and connectivity of deep-sea hydrothermal vent metapopulations. Molecular ecology, 19: 4391-4411.

WARREN, L.V.; ASSINE, M.L.; SIMÕES, M.G.; RICCOMINI, C. \& ANELLI, L.E. (2015) A Formação Serra Alta, Permiano, no Centro-Leste do Estado de São Paulo, Bacia do Paraná, Brasil. Brazilian Journal of Geology, 45: 127-142.

WATKINS, R. (1974) Palaeobiology of an offshore molluscan fauna from the California Oligocene. Palaeogeography, Palaeoclimatology, Palaeoecology, 15: $245-266$.

WOODS HOLE OCEANOGRAPHIC INSTITUTION (2014) Natural oil seeps. http://www.whoi.edu/oil/natural-oil-seeps, last access May 052016.

ZALÁN,P.V., WOLFF,S., CONCEIÇÃO, J.C.J., APPI, V.T., ASTOLFI, M.A.M. \& MARQUES, A. (1990) The Paraná Basin. In: LEIGHTON,M.W., KOLATA,D.R., OLTZ, D.F. \& EIDEL ,J. Interior cratonic basins. AAPG Memoir,51: 681-708. 
PARTE 5

5. CONCLUSÕES 


\subsection{CONCLUSÕES}

Nesse documento foram analisadas sucessões sedimentares particulares das formações Irati e Serra Alta, nos estados do Paraná e São Paulo, compostas por folhelhos negros, argilitos e siltitos, à primeira vista afossilíferos, cuja deposição se deu em condições de decantação de sedimentos finos, em ambientes distais (abaixo do nível de base de ondas de tempestades), calmos e pouco oxigenados. A análise detalhada e integrada destes depósitos gerou uma série de informações importantes a cerca da gênese das ocorrências fossilíferas, composição e abundância dos fósseis de macroinvertebrados bentônicos e da dinâmica paleombiental. Aqui são apresentadas as principais conclusões obtidas nos diferentes artigos científicos gerados como produtos da tese. Conforme já referido, anteriormente, os artigos na integra estão disponíveis nos anexos 1, 2, 3, e 4 .

\subsubsection{Principais Conclusões Relacionadas aos Bivalves da Crise Anóxica da FORMAÇÃO IRATI (ANEXO 2)}

Durante a deposição da sucessão de pelitos da Formação Irati, prevaleceram condições de substrato lamoso e baixíssimas concentrações de oxigênio. Durante esse intervalo, moluscos bivalves viveram nas margens da Bacia do Paraná, de forma contemporânea a deposição de finos, ricos em matéria orgânica, em ambientes mais distais (abaixo do nível de base de ondas de tempestade). As conchas foram preservadas em depósitos de costa à fora, vindas de regiões mais rasas e oxigenadas da bacia, através do transporte por fluxos e correntes de tempestades. Posteriormente, as conchas foram selecionadas e orientadas por correntes de fundo no ambiente de offshore. Portanto, os pavimentos de conchas de moluscos bivalves encontrados na Formação Irati são concentrações fósseis que possuem história deposicional complexa (sensu Kidwell, 1991), apesar de sua estrutura interna (microestratigrafia) simples.

Os dados obtidos têm importantes implicações paleoecológicas, paleogeograficas e evolutivas.

a- Abundante população de moluscos bivalves colonizaram as margens da Bacia do Paraná, coevas a decantação de finos na plataforma, onde condições disóxicas/óxicas devem ter existido durante a deposição dos folhelhos betuminosos da Formação Irati; 
b- A natureza mono- a paucispecífica dos pavimentos ricos em bivalves estudados é, em parte, função de seleção granulométrica por transporte hidráulico. Portanto, os pavimentos estudados contêm informações limitadas sobre a malacofauna que viveu nas margens da bacia nos "tempos Irati";

c- A presença de bivalves pachydomídeos de infauna nos pavimentos estudados indica que a fauna já era endêmica e a conexão da bacia com o oceano aberto (Panthalassa) restrita ou ausente. Portanto, a origem da malacofauna endêmica do Grupo Passa Dois deve ter ocorrido em algum momento entre a deposição da Formação Palermo, subjacente, e a Formação Irati, sobrejacente, e não durante a deposição das formações Serra Alta e Teresina, sobrejacentes, como se acreditava anteriormente (veja as discussões de Runnegar \& Newell, 1971; Simões et al., 1998).

Durante a deposição da Formação Serra Alta, como resultado da melhoria na circulação das águas de fundo na Bacia do Paraná, os bivalves pachydomídeos se diversificaram dramaticamente, especialmente em ambientes disóxicos (veja Bondioli, 2014; Bondioli et al., 2015; Warren et al., 2015). Este representa o primeiro evento verdadeiro de expansão dos bivalves endêmicos, posterior à crise anóxica da Formação Irati. Finalmente, nossos resultados alteram consideravelmente a distribuição vertical dessa fauna, cuja primeira aparição deve ter ocorrido na base da Formação Irati, antes do que se imaginava.

\subsubsection{Principais conclusões Relacionadas aOS Estudos Realizados Na FormaÇão Serra Alta (Anexos 2, 3 e 4)}

A análise integrada (sedimentológica, paleontológica e tafonômica) da sucessão estudada mostra que os depósitos da Formação Serra Alta, dominados por sedimentos finos, não são o registro de condições distais, pobres em oxigênio, em ambientes relativamente estáveis e de longa duração, como antigamente pensado. Na verdade, a história deposicional da Formação Serra Alta é dinâmica, pontuada por variações nas concentrações de oxigênio e nas taxas de sedimentação, que afetaram as faunas bentônicas e a gênese das rochas estudadas.

Populações de bivalve oportunistas (= event populations, sensu Kauffman \& Sageman, 1990) estão associadas a camadas e intervalos estratigráficos particulares. Invariavelmente estão relacionadas à processos sedimentares de alta energia. 
Consequentemente, a colonização dos fundos por tais populações de invertebrados bentônicos está associada a mudanças nos substratos e na concentração de oxigênio (ambiente anaeróbio pra disaeróbio/aeróbio). Um bom exemplo seria a camada centimétrica de arenito fino com estratificação cruzada de baixo ângulo, densamente bioturbada no topo, que ocorre no afloramento situado na Rodovia Castello Branco (SP-280), km 160,7.

Nas rochas estudadas, as condições de fundo são materializadas por siltitos maciços, dominadas por baixas taxas de sedimentação, sob condições anóxicas a disóxicas. Estes depósitos, muito pouco bioturbados (com Planolites isolados), podem conter dois tipos de faunas de bivalves associadas a condições de baixas taxas de oxigenação, (a) população residente (Kauffman \& Sageman, 1990), representada por bivalves suspensívoros de infauna (e.g. Barbosaia angulata, Rioclaroa lefevrei), adaptados a condições disaeróbias e, (b) bivalves de grandes dimensões, de infauna (e.g. Tambaquyra), cujas conchas geralmente são finas e, por vezes, com feições morfológicas incomuns (e.g., torção da concha, rostrum). Dentre essas, os gêneros Anhembia, Tambaquyra e Maackia. Bivalves referidos à população residente são comumente pequenos e se encontram dispersos no siltito maciço, com as valvas articuladas fechadas ou abertas. Estes bivalves viveram em condições nas quais as camadas superiores do substrato e grande parte da coluna d'água sobrejacente ao substrato devem ter sido disaeróbios. A diversidade da fauna é baixa, mas a abundância de algumas espécies de bivalves em certas camadas é alta, provavelmente refletindo o desenvolvimento "explosivo" devido à melhoria nas condições de oxigenação de fundo. Por sua vez, os bivalves atribuídos aos gêneros Anhembia, Tambaquyra e Maackia devem ter vivido em ambiente onde a zona anóxica é, abruptamente marcada e situada próxima ou na interface água-sedimento. Porém, a coluna d'água sobrejacente ao substrato pode ter sido melhor oxigenada. Neste caso, o substrato pelítico saturado de $\mathrm{H}_{2} \mathrm{~S}$ foi colonizado por uma fauna pouco diversificada, provavelmente adaptada à quimiossimbiose.

$\mathrm{O}$ resultado mais importante dessa tese diz respeito às evidências sedimentológicas, estratigráficas, paleontológicas, tafonômicas e geoquímicas que apontam para a presença de uma fauna de bivalves vivendo associada a um sistema de exsudações de metano e/ou outros hidrocarbonetos, na Formação Serra Alta (vide também Alessandretti et al., em preparação). Valores negativos de $\delta^{13} \mathrm{C}$ obtidos para o calcário brechado, e conchas de bivalves do mesmo intervalo estratigráfico representado por argilitos cinza, às vezes bem laminados ou maciços, indicam que a gênese desses depósitos se deu em condições de costa à fora, influenciada pelo metabolismo de bactérias redutoras de sulfato/oxidantes de metano. A 
associação de Tambaquyra camargoi com estruturas elevadas do substrato (e.g., mounds) é a evidência definitiva de que os bivalves gigantes da Formação Serra Alta foram quimiossimbiontes. T. camargoi, é considerada a partir de então o primeiro Pachydomidae quimiossimbionte conhecido, e a fauna de bivalves gigantes da Formação Serra Alta, a primeira fauna quimiossimbionte descrita para o Permiano. A fauna em questão é composta também por Maackia contorta, espécie que ocorre nas mesmas camadas onde T. camargoi e Anhembia froesi são abundantes. A característica mais marcante desta espécie é a torção de valvas, atributo típico de alguns organismos quimiossimbiontes (vide Seilacher, 1990).

\subsection{REFERÊNCIAS BIBLIOGRÁFICAS}

ALESSANDRETTI, L. et al. (em preparação) A singular Permian methane seep system in the Paraná Basin revealed by clastic dykes and fossil-rich carbonate concretions.

ABERHAN, M. \& KIESSLING, W. (2015) Persistent ecological shifts in marine molluscan assemblages across the end-Cretaceous mass extinction. In: JABLONSKI, D. (ED.), Proceedings of the National Academy of Sciences. University of Chicago, Chicago, p. 16.

ALESSANDRETTI, L.; WARREN, L.V.; MACHADO, R.; NOVELOO, V.F. \& SAYEG, I.J. (2015) Septarian carbonate concretions in the Permian Rio do Rasto Formation: birth, growth and implications for the early diagenetic history of southwestern Gondwana succession. Sedimentary Geology, 326: 1-15.

BONDIOLI, J.G. (2014) Dinâmica sedimentar, tafonomia e paleoambientes da facies de offshore da Formacão Serra Alta, Permiano, Bacia do Paraná: um estudo de caso no Estado de São Paulo, Brasil. 130 p. Dissertação de Mestrado. Instituto de Geociências, USP, São Paulo, SP.

BONDIOLI, J.G.; MATOS, S.A.; WARREN, L.V.; ASSINE, M.L.; RICCOMINI, C. \& SIMÕES M.G. (2015) The interplay between event and background sedimentation and the origin of fossil-rich carbonate concretions: a case study in Permian rocks of the Paraná Basin, Brazil. Lethaia, 48: 522-539.

BRETT, C.E. (2003) Taphonomy: sedimentological implications of fossil preservation. In Middleton, G.V. (ed.), Encyclopedia of Sediments and Sedimentary Rocks. Kluwer, Dordrecht, p. 723-729. 
EL ALBANI, A.; VACHARD, D.; KUHNT, W. \& THUROW, J. (2001) The role of diagenetic carbonate concretions in the preservation of the original sedimentary record. Sedimentology, 48: 875-886.

FOSTER,W.J. \& TWITCHETT, R.J. (2014) Functional diversity of marine ecosystems after the late Permian mass extinction event. Nature Geoscience, 7: 233--238.

HOLZ, M.; FRANÇA, A.B.; SOUZA, P.A.; IANNUZZI, R. \& ROHN, R. (2010) A stratigraphic chart of the late Carboniferous/Permian succession of the eastern border of the Paraná Basin, Brazil, South America. Journal of South American Earth Sciences, 29: 381-399.

KAUFFMAN, E.G. \& SAGEMAN, B.B. (1990) Biological sensing of benthic environments in dark shales and related oxygen-restricted facies. In: Ginsburg, R.N. \& Beaudoin, B. (eds.), Cretaceous Resources, Events, and Rhythms. Kluwer Press, Amsterdam, p. 125138.

KIDWELL, S.M. \& HOLLAND, S.M. (1991) Field description of coarse bioclastics fabrics. Palaios, 6: 426-434.

MEGLHIORATTI, T. (2006) Estratigrafia de Seqüências das formações Serra Alta, Teresina e Rio do Rasto (Permiano, Bacia do Paraná) na porção nordeste do Paraná e centro-sul de São Paulo. 133p. Dissertação de Mestrado, Instituto de Geociências e Ciências Exatas, UNESP, Rio Claro, SP.

MENDES, J.C. (1954) Contribuição à estratigrafia da Série Passa Dois no Estado do Paraná. Boletim da Faculdade de Filosofia, Ciências e Letras da Universidade de São Paulo, 175, Geologia, 10: 1-119.

MILANI, E.J.; MELO, J.H.G.; SOUZA, P.A.; FERNANDES; L.A. \& FRANÇA, A.B. (2007) Bacia do Paraná. Boletim de Geociências da Petrobrás, 15: 265-287.

ROHN, R. (1994) Evolução ambiental da Bacia do Paraná durante o Neopermiano no leste de Santa Catarina e do Paraná. 2v. Tese de Doutoramento, Instituto de Geociências, USP, São Paulo, SP.

RUNNEGAR, B. \& NEWELL, N.D. (1971) Caspian- like relict moluscan fauna in the South America Permian. Bulletin of the American Museum of Natural History, 146: 1-66.

SANFORD, R.M. \& LANGE, F.W. (1960) Basin study approach to oil evaluation of Paraná Miogeosyncline south Brasil. Bulletin of the American Association of Petroleum Geologist, 44: 1316-1374. 
SEILACHER, A. (1990) Aberrations in bivalve evolution related to photo- and chemosymbiosis. Historical Biology, 3: 289-311.

SCHNEIDER, R.L.; MÜHLMANN, H.; TOMMASI, E.; MEDEIROS, R.A.; DAEMON, R.F. \& NOGUEIRA, A.A. (1974) Revisão estratigráfica da Bacia do Paraná. In: $28^{\circ}$ Congresso Brasileiro de Geologia. Anais, 1: 41-65.

SIMÕES, M.G.; ROCHA-CAMPOS, A.C. \& ANELLI, L.E. (1998) Paleoecology and evolution of Permian bivalve faunas (Paraná Basin) In Brazil. In: JOHNSTON, P.A. \& HAGGART. J.W. (eds.), Bivalves - An Eon of evolution - paleobiological studies honoring Norman D. Newell. Calgary University Press, Canada, 443-452.

SOUSA, S.H.M. (1985) Fácies sedimentares das Formações Estrada Nova e Corumbataí no Estado de São Paulo. 142 p. Dissertação de Mestrado, Instituto de Geociências, USP, São Paulo, SP.

WARREN, L.V.; ALMEIDA, R.P.; HACHIRO, J.; MACHADO, R.; ROLDAN, L.F.; STEINER, S.S. \& CHAMANI, M.A.C. (2008) Evolução sedimentar da Formação Rio do Rasto (Permo-Triássico da Bacia do Paraná) na porção centro sul do Estado de Santa Catarina, Brasil. Revista Brasileira de Geociências, 38: 213-227.

WARREN, L.V.; ASSINE, M.L.; SIMÕES, M.G.; RICCOMINI, C. \& ANELLI, L.E. (2015) A Formação Serra Alta, Permiano, no Centro-Leste do Estado de São Paulo, Bacia do Paraná, Brasil. Brazilian Journal of Geology, 45: 127-142. 